Article

\title{
Density, Viscosity, and Excess Properties of Ternary Aqueous Mixtures of MDEA + MEA, DMEA + MEA, and DEEA + MEA
}

\author{
Sumudu S. Karunarathne, Dag A. Eimer, Klaus J. Jens and Lars E. Øi * \\ Faculty of Technology, Natural Sciences and Maritime Studies, University of South-Eastern Norway, Kjølnes \\ Ring 56, 3901 Porsgrunn, Norway; sumuduunimrt@gmail.com (S.S.K.); Dag.A.Eimer@usn.no (D.A.E.); \\ Klaus.J.Jens@usn.no (K.J.J.) \\ * Correspondence: lars.oi@usn.no; Tel.: +47-35-575-141
}

Received: 3 January 2020; Accepted: 10 February 2020; Published: 19 February 2020

\begin{abstract}
This study presents the measured densities and viscosities of three ternary aqueous mixtures of tertiary and primary amines. The tertiary amines of N-methyldiethanolamine (MDEA), dimethylethanolamine (DMEA), diethylethanolamine (DEEA), and the primary amine monoethanolamine (MEA) at different concentrations (mass\%) were mixed to prepare the liquid mixtures. The excess molar volume $V^{E}$ of the mixtures was analyzed using measured densities to acquire a better understanding of the molecular packing and intermolecular interactions in the mixtures. The excess free energy of activation $\Delta G^{E *}$ and excess entropy of activation $\Delta S^{E *}$ for viscous flow were determined from the measured viscosities by implementing the theory of rate processes of Eyring. Correlations based on the Redlich-Kister type polynomial were adopted to correlate the excess properties $V^{E}$ and $\Delta G^{E *}$ as a function of the amine mole fraction and temperature. The results showed that the correlations were able to represent the measured data with satisfactory accuracies for engineering calculations.
\end{abstract}

Keywords: density; viscosity; MDEA; DMEA; DEEA; excess property; Redlich-Kister

\section{Introduction}

The chemical absorption of $\mathrm{CO}_{2}$ into aqueous alkanolamines is a mature technology that has been used for decades in the natural gas industry. The solvent-based commercial scale postcombustion $\mathrm{CO}_{2}$ capture plants are generally operated with 15-20 mass\% aqueous monoethanolamine (MEA), 30 mass\% aqueous MEA, KS-1 based on sterically hindered amines, and DC-103 from Shell Cansolv (50 mass\% amine and 50 mass $\% \mathrm{H}_{2} \mathrm{O}$ ) [1-3]. Bernhardsen and Knuutila [4] reviewed the potential amine solvents for $\mathrm{CO}_{2}$ absorption process by considering the absorption capacity, cyclic capacity, and pKa. The studies performed on 3-amino-1-propanol (3A1P) $[5,6]$ and diethylenetriamine (DETA) $[7,8]$ stated the possibilities of using them as solvents in post-combustion $\mathrm{CO}_{2}$ capture. The applicability of this technology to post-combustion $\mathrm{CO}_{2}$ capture is challenging owing to the economic feasibility of the process due to the high-energy penalty in the $\mathrm{CO}_{2}$ stripping. MEA is a primary amine that shows a high $\mathrm{CO}_{2}$ absorption rate, which is promising for the process. The main disadvantage of MEA is that it requires a high amount of energy to release $\mathrm{CO}_{2}$ during the stripping. Tertiary amines like N-methyldiethanolamine (MDEA), dimethylethanolamine (DMEA), and diethylethanolamine (DEEA) have a low heat of reaction, which lowers the energy requirement in the stripping process [9-11]. MDEA is traditionally used for $\mathrm{CO}_{2}$ removal at high pressures. It is normally not used for $\mathrm{CO}_{2}$ removal at atmospheric pressure [12]. The MDEA solutions are used for the selective removal of $\mathrm{H}_{2} \mathrm{~S}$ from gas streams like natural gases, synthesis gases from the gasification 
of coal and heavy oils, and tail gases from sulphur plants that contain both $\mathrm{CO}_{2}$ and $\mathrm{H}_{2} \mathrm{~S}$ [13,14]. In addition to the selective removal of $\mathrm{H}_{2} \mathrm{~S}$, several advantages of MDEA over primary and secondary amines were reported, such as low vapor pressure, high $\mathrm{CO}_{2}$ absorption capacity, high resistance to degradation, and fewer corrosion problems $[15,16]$. The low $\mathrm{CO}_{2}$ absorption rate of tertiary amines makes it inefficient to use them alone with $\mathrm{H}_{2} \mathrm{O}$ as a solvent in the absorption-desorption process to deal with gas streams with low $\mathrm{CO}_{2}$ concentrations. The work performed by Kim and Savage [17] on reaction kinetics of $\mathrm{CO}_{2}$ absorption in aqueous DEEA claimed that DEEA has a higher reaction rate than MDEA. Alongside the results found by Henni et al. [18] on kinetics of DMEA, it was observed that DMEA and DEEA have a higher absorption performance compared to MDEA [9]. Chakravarty et al. [19] demonstrated that $\mathrm{CO}_{2}$ absorption can be enhanced by adding a primary or secondary amine to the tertiary amine without changing the stripping characteristics. Studies have been performed to investigate the performance of aqueous blends of tertiary and primary amines in $\mathrm{CO}_{2}$ absorption [9,20-22]. Conway et al. [21] showed improvements in the cyclic capacity of DMEA + MEA $+\mathrm{H}_{2} \mathrm{O}$ and DEEA $+\mathrm{MEA}+\mathrm{H}_{2} \mathrm{O}$ mixtures compared to aqueous MEA mixtures.

Physical properties, such as the density and viscosity of solvents, are essential for engineering calculations when performing mathematical modelling and simulations for the sizing of process equipment. The density and viscosity are required in many mass and heat transfer correlations that are used in the designing of absorbers, strippers, and heat exchangers in the process. Further properties are useful in flow calculations to select material transfer equipment like pumps and valves. The density and viscosity data of some MDEA $+\mathrm{MEA}+\mathrm{H}_{2} \mathrm{O}$ mixtures have been reported in literature sources [23-25]. For the mixtures of DMEA + MEA $+\mathrm{H}_{2} \mathrm{O}$ and DEEA $+\mathrm{MEA}+\mathrm{H}_{2} \mathrm{O}$, literature for measured properties are scarce [21].

In this study, the measurements of density and viscosity of three different aqueous tertiary and primary amines mixtures of MDEA (1) + MEA (2) + $\mathrm{H}_{2} \mathrm{O}$ (3), DMEA (1) + MEA (2) + $\mathrm{H}_{2} \mathrm{O}$ (3), and DEEA (1) + MEA (2) $+\mathrm{H}_{2} \mathrm{O}$ (3) at different amine concentrations and temperatures were performed. The excess properties of molar volume, viscosity, and free energy of activation and entropy for viscous flow were determined to examine the molecular structure and interactions in the mixtures. Finally, the data were fitted to the density and viscosity correlations available in the literature and parameters were determined via regression. The accuracy of the data fitting was examined through average absolute relative deviation $(A A R D(\%))$ and absolute maximum deviation $(A M D)$.

\section{Materials and Methods}

\subsection{Material Description}

Table 1 lists the materials that were used in this study. Liquid mixtures of aqueous tertiary and primary amines of MDEA + MEA $+\mathrm{H}_{2} \mathrm{O}$, DMEA $+\mathrm{MEA}+\mathrm{H}_{2} \mathrm{O}$, and DEEA + MEA + $\mathrm{H}_{2} \mathrm{O}$ were prepared on the mass basis using a balance, model: XS-403S from Mettler Toledo (Greifensee, Switzerland) with a resolution of $1 \mathrm{mg}$. Amines were used without further purification and dissolved with deionized (resistivity: $18.2 \mathrm{M} \Omega \cdot \mathrm{cm}$ ) and degassed water from a rotary evaporator (Rotavapor R210, Buchi, Flawil, Switzerland).

Table 1. Materials used in this study.

\begin{tabular}{cccc}
\hline Chemical Name & CAS No. & Source & Purity \\
\hline MDEA & $105-59-9$ & Merck Schuchardt OHG, Hohenbrunn, Germany & $\geq 98 \%$ \\
DMEA & $108-01-0$ & Alfa Aesar, Kandel, Germany & $\geq 99$ \\
DEEA & $100-37-8$ & Sigma-Aldrich, Darmstadt, Germany & $\geq 99.5 \%$ \\
MEA & $141-43-5$ & Sigma-Aldrich, Darmstadt, Germany & $\geq 99.5 \%(G C)$ a \\
\hline \multicolumn{4}{c}{${ }^{a}$ GC: Gas chromatography. }
\end{tabular}




\subsection{Density Measurement}

Density of the mixtures was measured using a density meter of DMA 4500 from Anton Paar (Graz, Austria) under atmospheric conditions. DMA 4500 has a temperature controller with an accuracy of $\pm 0.03 \mathrm{~K}$ and the accuracy of the density measurement is $\pm 0.05 \mathrm{~kg} \cdot \mathrm{m}^{-3}$. A liquid sample with a volume of approximately $5 \mathrm{~mL}$ was used to take the density reading and a new sample was fed into the U-tube for density measurements at each temperature and composition. In order to check the reliability of the instrument, a density check was performed frequently at $293.15 \mathrm{~K}$ using degassed deionized water. As suggested by the manufacturer, the density check is accepted when the deviations between the experimental and stored reference density data is smaller than $0.1 \mathrm{~kg} \cdot \mathrm{m}^{-3}$. For deviations greater than $0.1 \mathrm{~kg} \cdot \mathrm{m}^{-3}$, a calibration was performed using both air and degassed deionized water at $293.15 \mathrm{~K}$ as per the instruction given by the manufacturer. The density of water was measured at different temperatures and compared with the literature data from the International Association for the Properties of Water and Steam (IAPWS) [26]. The comparison showed that the deviation of the measured density of water was less than $0.01 \%$, which was acceptable.

\subsection{Viscosity Measurement}

A double-gap rheometer (pressure cell XL, Anton Paar, Graz, Austria) Physica MCR 101 was used for the dynamic viscosity measurements of the aqueous amine mixtures. A liquid sample of 7 $\mathrm{mL}$ in volume was transferred using a syringe in the space occupied between the rotating and fixed cylinders in the pressure cell. For the viscosity measurements at temperatures higher than $303.15 \mathrm{~K}$, the internal temperature controller with an accuracy of $\pm 0.03 \mathrm{~K}$ was used to maintain different temperatures up to $363.15 \mathrm{~K}$. An external cooling system Viscotherm VT 2 (Anton Paar, Graz, Austria) with an accuracy of $\pm 0.02 \mathrm{~K}$ was adopted to acquire precise measurements for the temperature range from $293.15 \mathrm{~K}$ to $303.15 \mathrm{~K}$. Following the instructions provided by Anton Paar, an air check and motor adjustment were performed prior to the experiments. The accuracy of the torque measurement is given by the manufacturer as $\max (0.2 \mu \mathrm{Nm} ; 0.5 \%)$ and the repeatability of the viscosity measurements is $\pm 0.008 \mathrm{mPa} \cdot \mathrm{s}$. Further, a standard viscosity solution S3S from Paragon Scientific Ltd. (Prenton, United Kingdom) was used to calibrate the measuring system. The viscosity of the standard viscosity fluid was measured at specific temperatures suggested by the supplier and was compared with the reference data to record deviations. The measured viscosities were corrected for these deviations obtained during the calibration. The experiments were conducted at atmospheric pressure (1 atm).

\subsection{Experimental Uncertainty}

Several uncertainty sources of material purity $u(p)$, temperature measurement $u(T)$, weight measurement $u(w)$, and repeatability $u(r e p)$ were taken into account to determine the combined standard uncertainty of density and viscosity measurements of aqueous amine mixtures.

For the uncertainty of density measurement, the specified standard uncertainties were $u(p)=$ $\pm 0.003, u(T)= \pm 0.012 \mathrm{~K}, u(w)= \pm 2 \times 10^{-4} \mathrm{~kg}$, and $u(\mathrm{rep})= \pm 0.13 \mathrm{~kg} \cdot \mathrm{m}^{-3}$. The maximum gradient of density against temperature, $\partial \rho / \partial T$, was found to be $0.88 \mathrm{~kg} \cdot \mathrm{m}^{-3} \cdot \mathrm{K}^{-1}$ and the corresponding uncertainty in $\rho,(\partial \rho / \partial T) \cdot u(T)$, was determined to be $\pm 0.0106 \mathrm{~kg} \cdot \mathrm{m}^{-3}$. The combined standard uncertainty for the density measurement was calculated as described in the Guide to the Expression of Uncertainty in Measurement $[27,28]$ by considering all mentioned uncertainty sources to be $u(\rho)$ $= \pm 2.97 \mathrm{~kg} \cdot \mathrm{m}^{-3}$. Then, the combined expanded uncertainty of the density measurement $U(\rho)$ was found to be $\pm 5.94 \mathrm{~kg} \cdot \mathrm{m}^{-3}$ (level of confidence $=0.95$ ).

In the uncertainty of viscosity measurement, specified standard uncertainties for the uncertainty sources were $u(p)= \pm 0.003, u(T)= \pm 0.012 \mathrm{~K}, u(w)= \pm 2 \times 10^{-4} \mathrm{~kg}$, and $u(r e p)= \pm 0.008 \mathrm{mPa} \cdot \mathrm{s}$. The combined standard uncertainty for the viscosity measurement was calculated to be $u(\eta)= \pm 0.008$ $\mathrm{mPa} \cdot \mathrm{s}$. Then, the combined expanded uncertainty of the viscosity measurement $U(\eta)$ was found to be $\pm 0.016 \mathrm{mPa} \cdot \mathrm{s}$ (level of confidence $=0.95$ ). 


\section{Results}

\subsection{Density and Excess Molar Volume}

The density of pure MDEA, DEEA, DMEA, and MEA are available in the literature. The measured densities of pure amines over a temperature range from $293.15 \mathrm{~K}$ to $343.15 \mathrm{~K}$ are listed in Table 2 with the relevant literature data and references. The measured density in this work is in good agreement with values reported in literature, which indicates the density meter was properly calibrated during the experiments.

Table 2. Densities $\rho / \mathrm{kg} \cdot \mathrm{m}^{-3}$ of pure amines MDEA, DMEA and DEEA.

\begin{tabular}{|c|c|c|c|c|c|}
\hline Amine & $\mathrm{T}(\mathrm{K})$ & This Work & & Literature & \\
\hline & & & Pinto et al. [29] & Hawrylak et al. [30] & Maham et al. [31] \\
\hline \multirow{13}{*}{ MDEA } & 293.15 & 1040.6 & 1040.12 & & \\
\hline & 298.15 & 1036.8 & & 1036.88 & 1035.9 \\
\hline & 303.15 & 1033.2 & & & 1032.0 \\
\hline & 308.15 & 1029.4 & & 1029.01 & \\
\hline & 313.15 & 1025.6 & 1024.74 & & 1024.45 \\
\hline & 318.15 & 1021.8 & & 1022.64 & \\
\hline & 323.15 & 1018.0 & 1017.27 & & 1016.66 \\
\hline & 328.15 & 1014.1 & & & \\
\hline & 333.15 & 1010.3 & 1009.56 & & 1009.00 \\
\hline & 338.15 & 1006.4 & & & \\
\hline & 343.15 & 1002.5 & & & 1001.24 \\
\hline & $\mathrm{T} /(\mathbf{K})$ & This Work & & Literature & \\
\hline & & & Maham et al. [32] & Hawrylak et al. [30] & Bernal-García et al. [33] \\
\hline \multirow{13}{*}{ DMEA } & 293.15 & 887.3 & & & 887.816 \\
\hline & 298.15 & 883.0 & 882.57 & 883.34 & 883.578 \\
\hline & 303.15 & 878.8 & 878.35 & & 879.315 \\
\hline & 308.15 & 874.5 & & 875.46 & 875.017 \\
\hline & 313.15 & 870.1 & 869.86 & & 870.686 \\
\hline & 318.15 & 865.8 & & 867.28 & 866.316 \\
\hline & 323.15 & 861.4 & & & 861.902 \\
\hline & 328.15 & 856.9 & & & 857.460 \\
\hline & 333.15 & 852.5 & 851.89 & & 852.965 \\
\hline & 338.15 & 847.9 & & & 848.423 \\
\hline & 343.15 & 843.3 & & & 843.844 \\
\hline & $\mathrm{T} /(\mathbf{K})$ & This Work & & Literature & \\
\hline & & & Zhang et al. [34] & Hawrylak et al. [30] & Pinto et al. [29] \\
\hline \multirow{11}{*}{ DEEA } & 293.15 & 884.3 & 884.20 & & \\
\hline & 298.15 & 879.7 & 879.54 & 879.52 & 879.47 \\
\hline & 303.15 & 875.1 & 874.82 & & \\
\hline & 308.15 & 870.4 & & 871.40 & \\
\hline & 313.15 & 865.8 & 865.56 & & 865.54 \\
\hline & 318.15 & 861.1 & & 861.82 & \\
\hline & 323.15 & 856.3 & & & 856.12 \\
\hline & 328.15 & 851.5 & & & \\
\hline & 333.15 & 846.7 & & & 846.61 \\
\hline & 338.15 & 841.9 & & & \\
\hline & 343.15 & 837.1 & & & 837.03 \\
\hline
\end{tabular}

The measured densities of MDEA + MEA + $\mathrm{H}_{2} \mathrm{O}$, DMEA + MEA + $\mathrm{H}_{2} \mathrm{O}$, and DEEA + MEA + $\mathrm{H}_{2} \mathrm{O}$ mixtures over different amine concentrations (mass \% of amine) and temperatures from $293.15 \mathrm{~K}$ to 343.15 $\mathrm{K}$ are listed in Tables 3-5, respectively. For the density of MDEA + MEA $+\mathrm{H}_{2} \mathrm{O}$ mixtures, the density increased with the increase of the MDEA concentration in the mixture. Moreover, for the 
DMEA + MEA $+\mathrm{H}_{2} \mathrm{O}$ and DEEA $+\mathrm{MEA}+\mathrm{H}_{2} \mathrm{O}$ mixtures, the density increased with the decrease of the DMEA and DEEA concentration in the mixtures.

Table 3. Densities $\rho\left(\mathrm{kg} \cdot \mathrm{m}^{-3}\right)$ and excess molar volume $V^{E}\left(\mathrm{~m}^{3} \cdot \mathrm{mol}^{-1}\right)$ of MDEA (1) $+\mathrm{MEA}(2)+\mathrm{H}_{2} \mathrm{O}$

(3) mixtures.

\begin{tabular}{|c|c|c|c|c|c|c|c|c|}
\hline Mixtures & \multicolumn{8}{|c|}{ MDEA/MEA } \\
\hline (Mass\%/Mass\%) & \multicolumn{2}{|c|}{$15 / 15$} & \multicolumn{2}{|c|}{$20 / 10$} & \multicolumn{2}{|l|}{$25 / 5$} & \multicolumn{2}{|l|}{$30 / 0$} \\
\hline${ }^{\mathrm{a}} x_{1} / x_{2}$ & 0.0296 & 0.0577 & $0.0398 / 0$. & & $0.0502 / 0.0196$ & & $0.0609 / 0$. & 000 \\
\hline $\mathrm{T}(\mathrm{K})$ & $\rho$ & $\begin{array}{c}V^{E} \\
\left(\times 10^{6}\right) \\
\end{array}$ & $\rho$ & $\begin{array}{c}V^{E} \\
\left(\times 10^{6}\right) \\
\end{array}$ & $\rho$ & $\begin{array}{c}V^{E} \\
\left(\times 10^{6}\right)\end{array}$ & $\rho$ & $\begin{array}{c}V^{E} \\
\left(\times 10^{6}\right)\end{array}$ \\
\hline 293.15 & 1019.7 & -0.292 & 1022.1 & -0.321 & 1024.5 & -0.351 & 1026.9 & -0.382 \\
\hline 298.15 & 1017.6 & -0.288 & 1019.9 & -0.317 & 1022.3 & -0.347 & 1024.7 & -0.377 \\
\hline 303.15 & 1015.3 & -0.284 & 1017.6 & -0.313 & 1020.05 & -0.342 & 1022.4 & -0.371 \\
\hline 308.15 & 1012.8 & -0.282 & 1015.2 & -0.310 & 1017.6 & -0.339 & 1019.9 & -0.367 \\
\hline 313.15 & 1010.3 & -0.281 & 1012.6 & -0.308 & 1015.0 & -0.336 & 1017.3 & -0.364 \\
\hline 318.15 & 1007.6 & -0.280 & 1009.9 & -0.306 & 1012.2 & -0.332 & 1014.6 & -0.361 \\
\hline 323.15 & 1004.8 & -0.278 & 1007.1 & -0.304 & 1009.3 & -0.329 & 1011.7 & -0.357 \\
\hline 328.15 & 1001.9 & -0.277 & 1004.1 & -0.302 & 1006.3 & -0.324 & 1008.7 & -0.354 \\
\hline 333.15 & 998.8 & -0.276 & 1000.9 & -0.297 & 1003.2 & -0.323 & 1005.6 & -0.350 \\
\hline 338.15 & 995.6 & -0.273 & 997.5 & -0.288 & 999.7 & -0.312 & 1002.3 & -0.346 \\
\hline 343.15 & 991.7 & -0.257 & 993.1 & -0.261 & 995.4 & -0.287 & 998.7 & -0.336 \\
\hline
\end{tabular}

${ }^{\mathrm{a} x}=$ mole fraction.

Table 4. Densities $\rho\left(\mathrm{kg} \cdot \mathrm{m}^{-3}\right)$ and excess molar volume $V^{E}\left(\mathrm{~m}^{3} \cdot \mathrm{mol}^{-1}\right)$ of DMEA (1) + MEA (2) $+\mathrm{H}_{2} \mathrm{O}$ (3) mixtures.

\begin{tabular}{|c|c|c|c|c|c|c|c|c|}
\hline Mixtures & & & & MEA/M & & & & \\
\hline (Mass\%/Mass\%) & $15 / 15$ & & $20 / 10$ & & $25 / 5$ & & $30 / c$ & \\
\hline${ }^{\mathrm{a}} x_{1} / x_{2}$ & $0.0391 / 0.0571$ & & $0.0525 / 0.0383$ & & $0.0660 / 0.0193$ & & $0.0797 / 0$ & 0000 \\
\hline $\mathrm{T}(\mathrm{K})$ & 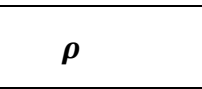 & $\begin{array}{c}V^{E} \\
\left(\times 10^{6}\right)\end{array}$ & $\rho$ & $\begin{array}{c}V^{E} \\
\left(\times 10^{6}\right)\end{array}$ & $\rho$ & $\begin{array}{c}V^{E} \\
\left(\times 10^{6}\right)\end{array}$ & $\rho$ & $\begin{array}{c}V^{E} \\
\left(\times 10^{6}\right)\end{array}$ \\
\hline 293.15 & 1001.9 & -0.463 & 998.4 & -0.550 & 994.4 & -0.626 & 990.9 & -0.715 \\
\hline 298.15 & 999.6 & -0.460 & 995.9 & -0.545 & 991.8 & -0.620 & 988.1 & -0.707 \\
\hline 303.15 & 996.7 & -0.448 & 993.2 & -0.539 & 989.0 & -0.613 & 985.2 & -0.698 \\
\hline 308.15 & 994.4 & -0.453 & 990.5 & -0.536 & 986.1 & -0.608 & 982.3 & -0.693 \\
\hline 313.15 & 991.6 & -0.452 & 987.6 & -0.533 & 983.1 & -0.603 & 979.2 & -0.687 \\
\hline 318.15 & 988.7 & -0.450 & 984.6 & -0.531 & 980.0 & -0.600 & 975.9 & -0.682 \\
\hline 323.15 & 985.5 & -0.444 & 981.4 & -0.528 & 976.8 & -0.596 & 972.6 & -0.678 \\
\hline 328.15 & 982.5 & -0.447 & 978.0 & -0.523 & 973.4 & -0.594 & 969.2 & -0.674 \\
\hline 333.15 & 979.3 & -0.448 & 974.6 & -0.520 & 970.0 & -0.591 & 965.7 & -0.671 \\
\hline 338.15 & 975.7 & -0.442 & 971.1 & -0.517 & 966.4 & -0.589 & 962.0 & -0.668 \\
\hline 343.15 & 972.4 & -0.445 & 967.4 & -0.511 & 962.8 & -0.589 & 958.4 & -0.669 \\
\hline
\end{tabular}

Table 5. Densities $\rho\left(\mathrm{kg} \cdot \mathrm{m}^{-3}\right)$ and excess molar volume $V^{E}\left(\mathrm{~m}^{3} \cdot \mathrm{mol}^{-1}\right)$ of DEEA (1) $+\mathrm{MEA}(2)+\mathrm{H}_{2} \mathrm{O}$ (3) mixtures.

\begin{tabular}{|c|c|c|c|c|c|c|c|c|}
\hline Mixtures & \multicolumn{8}{|c|}{ DEEA/MEA } \\
\hline (Mass\%/Mass\%) & \multicolumn{2}{|c|}{$15 / 15$} & \multicolumn{2}{|c|}{$20 / 10$} & \multicolumn{2}{|c|}{$25 / 5$} & \multicolumn{2}{|c|}{$30 / 0$} \\
\hline${ }^{\mathrm{a}} x_{1} / x_{2}$ & \multicolumn{2}{|c|}{$0.0301 / 0.0577$} & \multicolumn{2}{|c|}{$0.0404 / 0.0388$} & \multicolumn{2}{|c|}{$0.0510 / 0.0196$} & \multicolumn{2}{|c|}{$0.0618 / 0.0000$} \\
\hline $\mathrm{T}(\mathrm{K})$ & $\rho$ & $V^{E}\left(\times 10^{6}\right)$ & $\rho$ & $V^{E}\left(\times 10^{6}\right)$ & $\rho$ & $V^{E}\left(\times 10^{6}\right)$ & $\rho$ & $V^{E}\left(\times 10^{6}\right)$ \\
\hline 293.15 & 1002.3 & -0.489 & 998.4 & -0.575 & 994.2 & -0.654 & 989.6 & -0.724 \\
\hline 298.15 & 999.8 & -0.484 & 995.7 & -0.568 & 991.4 & -0.645 & 986.5 & -0.711 \\
\hline 303.15 & 997.1 & -0.479 & 992.9 & -0.561 & 988.4 & -0.636 & 983.4 & -0.702 \\
\hline 308.15 & 994.3 & -0.476 & 990.0 & -0.556 & 985.3 & -0.629 & 980.2 & -0.693 \\
\hline 313.15 & 991.4 & -0.473 & 986.9 & -0.551 & 982.1 & -0.623 & 976.9 & -0.684 \\
\hline 318.15 & 988.5 & -0.471 & 983.7 & -0.547 & 978.8 & -0.617 & 973.4 & -0.677 \\
\hline
\end{tabular}




\begin{tabular}{lllllllll}
\hline 323.15 & 985.1 & -0.464 & 980.5 & -0.544 & 975.3 & -0.611 & 969.8 & -0.669 \\
328.15 & 981.8 & -0.462 & 977.1 & -0.541 & 971.8 & -0.606 & 966.2 & -0.663 \\
333.15 & 978.5 & -0.459 & 973.6 & -0.538 & 968.2 & -0.602 & 962.4 & -0.657 \\
338.15 & 974.4 & -0.443 & 970.0 & -0.535 & 964.3 & -0.595 & 958.5 & -0.651 \\
343.15 & 971.1 & -0.448 & 966.2 & -0.529 & 960.4 & -0.589 & 954.6 & -0.645 \\
\hline \multicolumn{7}{c}{$x=$ mole fraction. }
\end{tabular}

The excess molar volume $V^{E}$ of the mixtures were determined using the molar volume of the mixture and pure components as follows:

$$
V^{E}=V-\sum_{i=1}^{n} x_{i} V_{i}^{0},
$$

where $V, V_{i}^{0}, V^{E}$, and $x_{i}$ refer to the molar volume of the mixture, molar volume of the pure component, excess molar volume of the mixture, and mole fraction, respectively. Here, $n=3$ to represent the ternary mixture and subscripts are as follows: $i=1$ for the tertiary amine, $i=2$ for the primary amine (MEA), and $i=3$ for $\mathrm{H}_{2} \mathrm{O}$.

The calculated $V^{E}$ from Equation (1) for MDEA + MEA + $\mathrm{H}_{2} \mathrm{O}$, DMEA + MEA + $\mathrm{H}_{2} \mathrm{O}$, and DEEA $+\mathrm{MEA}+\mathrm{H}_{2} \mathrm{O}$ mixtures are given in Tables 3-5, respectively. The following correlation was adopted to correlate the density data at different amine concentrations and temperatures. Redlich-Kister [35] polynomials are one of the most common approaches toward correlating the excess properties of binary mixtures because polynomial expressions are simple and easy to understand. Here, it was assumed that excess molar volume of a ternary mixture as a sum of excess molar volumes from different binary pairs, as given in Equation (3). The binary mixture polynomial shown in Equation (4) was extended by adding ternary coefficients for the ternary mixture with a temperature dependency, as described in Equation (5). Finally, the density was determined as follows:

$$
\rho=\frac{\sum_{i=1}^{n} x_{i} M_{i}}{V^{E}+\sum_{i=1}^{n} \frac{x_{i} M_{i}}{\rho_{i}}}
$$

where $\rho, \rho_{i}, V^{E}, x_{i}$, and $M_{i}$ are the density of the mixture, density of the pure amine, excess molar volume of the mixture, mole fraction, and molecular weight of the pure component, respectively. The subscripts are as follows: $i=1$ for tertiary amine, $i=2$ for primary amine (MEA), and $i=3$ for $\mathrm{H}_{2} \mathrm{O}$.

$$
\begin{gathered}
V^{E}=V_{12}^{E}+V_{23}^{E}+V_{13}^{E}, \\
V_{j k}^{E}=x_{j} x_{k} \sum_{i=0}^{n} A_{i}\left(x_{j}-x_{k}\right)^{i}, \\
A_{i}=a+b(T)+c(T)^{2},
\end{gathered}
$$

where $A_{i}$ are pair parameters and are assumed to be temperature dependent.

Other correlations have been suggested for the excess molar volume of ternary mixtures were reported by Domínguez et al. [36] and Samanta and Bandyopadhyay [37]. References [38-40] suggested correlations for $\mathrm{CO}_{2}$-loaded solutions, but in this work, emphasis is on non-loaded aqueous amine mixtures.

The accuracy of the proposed correlation for the fitting of measured densities was examined through the average absolute relative deviation (AARD (\%)) and the absolute maximum deviation $(A M D)$ as defined in Equations (6) and (7), respectively.

Average absolute relative deviation:

$$
\operatorname{AARD}(\%)=\frac{100 \%}{N} \sum_{i=1}^{N}\left|\frac{Y_{i}^{E}-Y_{i}^{C}}{Y_{i}^{E}}\right|,
$$

and the absolute maximum deviation: 


$$
A M D=M A X\left|Y_{i}^{E}-Y_{i}^{C}\right|
$$

where $N, Y_{i}^{E}$, and $Y_{i}^{C}$ indicate the number of data points, the measured property, and the calculated property, respectively.

Figure 1 shows a comparison between the measured versus correlated density data for aqueous amine mixtures. The study reveals that the proposed correlation fits the density data with an acceptable accuracy. The calculated parameters for the excess volume $V^{E}$ correlation are given in Tables 6-8. The reported $A A R D$ and $A M D$ for the density correlation of MDEA + MEA + $\mathrm{H}_{2} \mathrm{O}$, DMEA $+\mathrm{MEA}+\mathrm{H}_{2} \mathrm{O}$, and DEEA $+\mathrm{MEA}+\mathrm{H}_{2} \mathrm{O}$ are listed in Table 9. The regression performed with a linear temperature dependency in Equation (5) revealed a $13 \%$ increase of $A A R D$ for MDEA + MEA + $\mathrm{H}_{2} \mathrm{O}$ mixtures, as given in Table 9. This indicated that the proposed correlation gave a better fit for the density data.

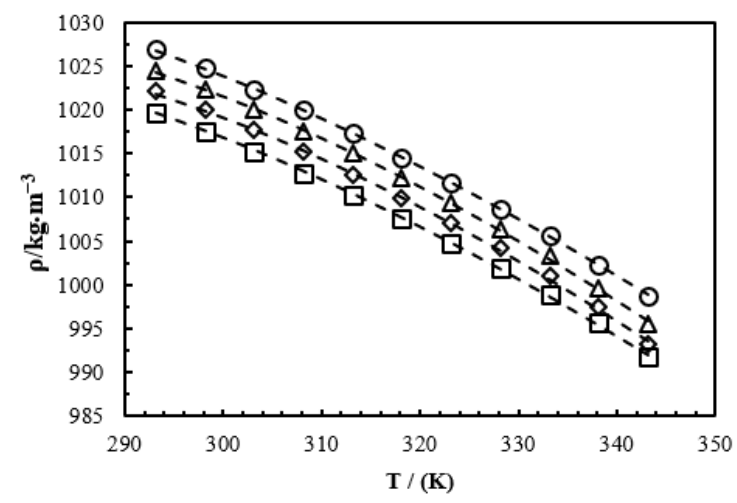

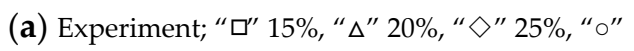
$30 \%$ (mass\% MDEA), correlation; "-- -".

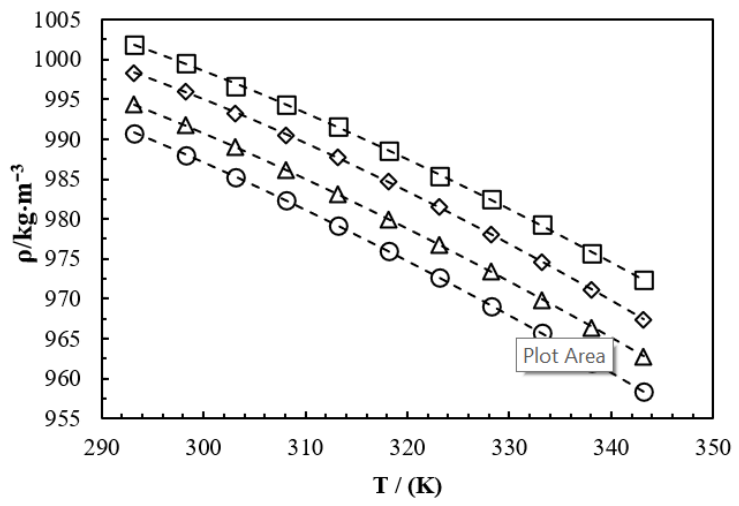

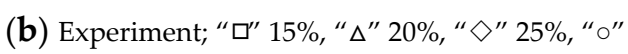
$30 \%$ (mass\% DMEA), correlation; “- - -".

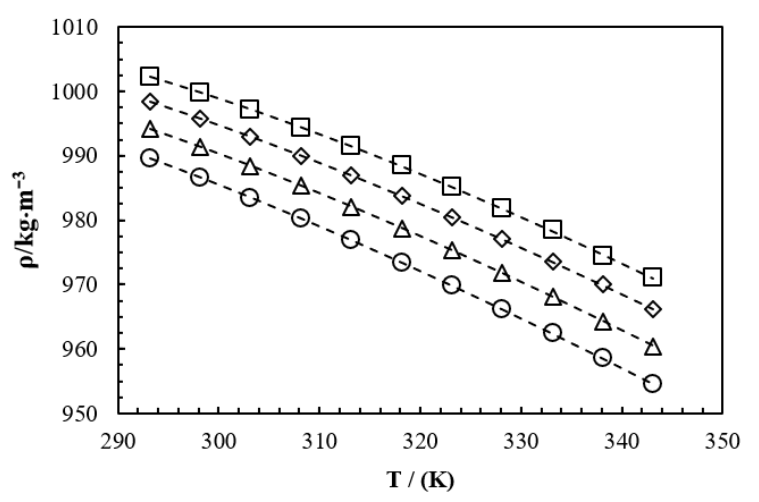

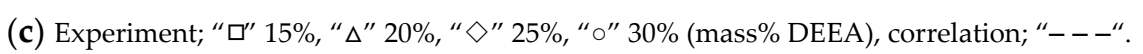

Figure 1. Density of: (a) MDEA + MEA + $\mathrm{H}_{2} \mathrm{O}$, (b) DMEA + $\mathrm{MEA}+\mathrm{H}_{2} \mathrm{O}$, and (c) DEEA + $\mathrm{MEA}+\mathrm{H}_{2} \mathrm{O}$ mixtures in the temperature range $293.15 \mathrm{~K}-343.15 \mathrm{~K}$.

Table 6. Binary parameters $A_{0}, A_{1}$, and $A_{2}$ of the equation $V_{j k}^{E}=x_{j} x_{k} \sum_{i=0}^{n} A_{i}\left(x_{j}-x_{k}\right)^{i}$ for the excess molar volume of MDEA (1) + MEA (2) + $\mathrm{H}_{2} \mathrm{O}(3)$.

\begin{tabular}{ccccc}
\hline \multirow{2}{*}{ Parameters } & \multicolumn{3}{c}{ Binary Pair } \\
\cline { 3 - 6 }$A_{0}$ & $a$ & -5740.7862 & 110.3506 & 0.7103 \\
& $b$ & -9.4267 & 0.5623 & 0.0984 \\
& $c$ & -6.0994 & 0.7119 & 0.6020 \\
\multirow{2}{*}{$A_{1}$} & $a$ & $47,728.6381$ & -91.5628 & 0.5925
\end{tabular}




\begin{tabular}{ccccc} 
& $b$ & 82.8194 & 0.5242 & 0.3620 \\
& $c$ & 70.3044 & 0.4374 & 0.6230 \\
$A_{2}$ & $a$ & $-41,5410.0557$ & 70.3808 & -0.2463 \\
\hline & $b$ & -724.8059 & 0.3897 & 0.2846 \\
& $c$ & -601.8188 & -0.0807 & -0.0710 \\
\hline
\end{tabular}

Table 7. Binary parameters $A_{0}, A_{1}$, and $A_{2}$ of the equation $V_{j k}^{E}=x_{j} x_{k} \sum_{i=0}^{n} A_{i}\left(x_{j}-x_{k}\right)^{i}$ for the excess molar volume of DMEA (1) + MEA (2) + $\mathrm{H}_{2} \mathrm{O}$ (3).

\begin{tabular}{|c|c|c|c|c|}
\hline \multirow{2}{*}{\multicolumn{2}{|c|}{ Parameters }} & \multicolumn{3}{|c|}{ Binary Pair } \\
\hline & & \multirow{2}{*}{$\begin{array}{c}\text { DMEA + MEA } \\
1236.6194\end{array}$} & \multirow{2}{*}{$\frac{\mathrm{MEA}+\mathbf{H}_{\mathbf{2}} \mathbf{O}}{-29.4723}$} & \multirow{2}{*}{$\frac{\text { DMEA + } \mathbf{H}_{2} \mathbf{O}}{-0.2082}$} \\
\hline$\overline{A_{0}}$ & $a$ & & & \\
\hline & $b$ & 1.2313 & 0.1074 & 0.3237 \\
\hline & $c$ & -4.8869 & 0.1673 & 0.3986 \\
\hline \multirow{3}{*}{$A_{1}$} & $a$ & $-10,260.3999$ & 24.7205 & 0.3942 \\
\hline & $b$ & -18.2970 & 0.9283 & 0.5201 \\
\hline & $c$ & 36.5240 & 0.3256 & 0.7509 \\
\hline \multirow[t]{3}{*}{$A_{2}$} & $a$ & $66,361.3723$ & -16.8614 & 0.7635 \\
\hline & $b$ & 110.1435 & 0.8558 & 0.1605 \\
\hline & $c$ & -240.1085 & 0.4951 & 0.3292 \\
\hline
\end{tabular}

Table 8. Binary parameters $A_{0}, A_{1}$, and $A_{2}$ of the equation $V_{j k}^{E}=x_{j} x_{k} \sum_{i=0}^{n} A_{i}\left(x_{j}-x_{k}\right)^{i}$ for the excess molar volume of DEEA (1) $+\mathrm{MEA}(2)+\mathrm{H}_{2} \mathrm{O}$ (3).

\begin{tabular}{ccccc}
\hline \multirow{2}{*}{ Parameters } & \multicolumn{3}{c}{ Binary Pair } \\
\cline { 3 - 5 }$A_{0}$ & $a$ & 1499.9879 & -31.3131 & -0.3593 \\
& $b$ & -7.4459 & 0.5442 & 0.2384 \\
& $c$ & 1.3969 & 0.0633 & 0.3485 \\
\multirow{4}{*}{$A_{1}$} & $a$ & $-12,608.1516$ & 24.6564 & -0.4664 \\
& $b$ & 68.6619 & 0.4921 & 0.7533 \\
& $c$ & -19.8546 & 0.5935 & 0.6335 \\
$A_{2}$ & $a$ & $107,748.3754$ & -15.3309 & -0.0644 \\
& $b$ & -588.5102 & 0.2714 & 0.5491 \\
& $c$ & 156.7816 & 0.5154 & 0.2691 \\
\hline
\end{tabular}

Table 9. Average absolute relative $(A A R D)$ and absolute maximum $(A M D)$ deviations calculated based on the correlation proposed from Equations (2)-(5).

\begin{tabular}{ccc}
\hline Mixture & AARD (\%) & AMD $\mathbf{( k g \cdot \mathbf { ~ m } ^ { - 3 } )}$ \\
\hline MDEA + MEA + $\mathrm{H}_{2} \mathrm{O}$ & 0.013 & 0.4 \\
DMEA + MEA + $\mathrm{H}_{2} \mathrm{O}$ & 0.004 & 0.3 \\
DEEA + MEA + $\mathrm{H}_{2} \mathrm{O}$ & 0.005 & 0.3 \\
\hline
\end{tabular}

The supplementary materials provide the information of the used MATLAB program for the calculation of parameters involve in density correlation.

The excess molar volume $V^{E}$ of the ternary mixtures showed a negative sign for the considered amine concentrations and temperatures. The negative sign of $V^{E}$ can be explained by the intermolecular packing effect and strong intermolecular interactions, such as H-bonding between unlike molecules. The relatively small structures of MEA and $\mathrm{H}_{2} \mathrm{O}$ compared to MDEA, DMEA, and DEEA could help to pack molecules efficiently, which resulted in the decrease of the mixture volume. In addition, the formation of $\mathrm{H}$-bonds among the tertiary amines, $\mathrm{MEA}$, and $\mathrm{H}_{2} \mathrm{O}$ could also lead the volume of tertiary mixtures to show a negative deviation of $V^{E}$. The highest negative values were reported in the mixtures with a 0 mass $\%$ MEA concentration. The $V^{E}$ increased with the increasing 
of MEA concentration in the mixtures. Further, $V^{E}$ increased with the increase of temperature. At high temperatures, the increase of the energy of molecular motion weakens the interaction strength of $\mathrm{H}$-bonds and inhibits the packing effect by leading to an increase of volume [41,42].

\subsection{Viscosity and Excess Free Energy of Activation for Viscous Flow}

Table 10 provides an overview of the measured viscosities of pure MDEA, DMEA, and DEEA from this study and literature at different temperatures from $293.15 \mathrm{~K}$ to $363.15 \mathrm{~K}$. As shown in Figure 2 , the measured viscosities in this work were in good agreement with data in the literature. It indicated that the measuring system was properly calibrated during the viscosity measurements. The measured viscosities for MDEA + MEA $+\mathrm{H}_{2} \mathrm{O}$, DMEA + MEA $+\mathrm{H}_{2} \mathrm{O}$, and DEEA + MEA $+\mathrm{H}_{2} \mathrm{O}$ mixtures are listed in Tables 11-13, respectively, with the relevant concentrations and temperatures. For the mixtures, the viscosity increased with the increase of the tertiary amine concentration and the viscosity decreased with the increase of temperature.

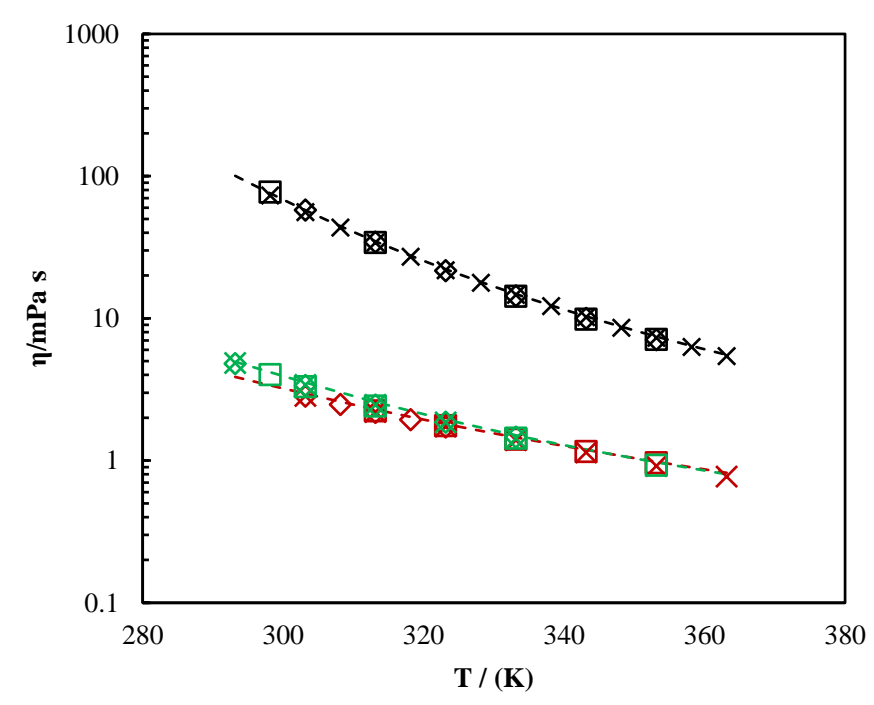

Figure 2. Viscosity of MDEA: “- - -“-this work; “ $\square$ " - Teng et al. [43]; “ $\diamond "-$ Li and Lie [24]; " $x^{\prime \prime}-$ Kummamuru et al. [44]. Viscosity of DMEA: "---“-this work; “ם”-Bernal-García et al. [33]; “ $\diamond "-$ Chowdhury et al. [45]; " $x$ "-DiGuilio et al. [46]. Viscosity of DEEA: “--_"-this work; “ $\square$ "-Maham et al. [32]; " $\diamond "-C h e n$ et al. [47]; " $x "-$ Ma et al. [48].

Table 10. Viscosities $\eta$ (mPa.s) of pure amines MDEA, DMEA, and DEEA.

\begin{tabular}{|c|c|c|c|c|c|}
\hline \multirow[t]{2}{*}{ Amine } & \multirow[t]{2}{*}{$\mathrm{T}(\mathrm{K})$} & \multirow[t]{2}{*}{$\begin{array}{l}\text { This } \\
\text { Work }\end{array}$} & \multicolumn{3}{|c|}{ Literature } \\
\hline & & & Teng et al. [43] & $\mathrm{Li}$ and Lie [24] & $\begin{array}{c}\text { Kummamuru et al. } \\
{[44]}\end{array}$ \\
\hline \multirow{11}{*}{ MDEA } & 293.15 & 100.630 & & & \\
\hline & 298.15 & 75.775 & 77.19 & & 73.10 \\
\hline & 303.15 & 57.658 & & 57.860 & 55.89 \\
\hline & 308.15 & 44.483 & & & 43.45 \\
\hline & 313.15 & 34.786 & 34.11 & 34.309 & 34.15 \\
\hline & 318.15 & 27.575 & & & 27.15 \\
\hline & 323.15 & 22.145 & & 21.672 & 21.82 \\
\hline & 328.15 & 18.024 & & & 17.79 \\
\hline & 333.15 & 14.820 & 14.30 & 14.386 & 14.63 \\
\hline & 338.15 & 12.319 & & & 12.20 \\
\hline & 343.15 & 10.325 & 9.849 & 9.979 & 10.21 \\
\hline
\end{tabular}




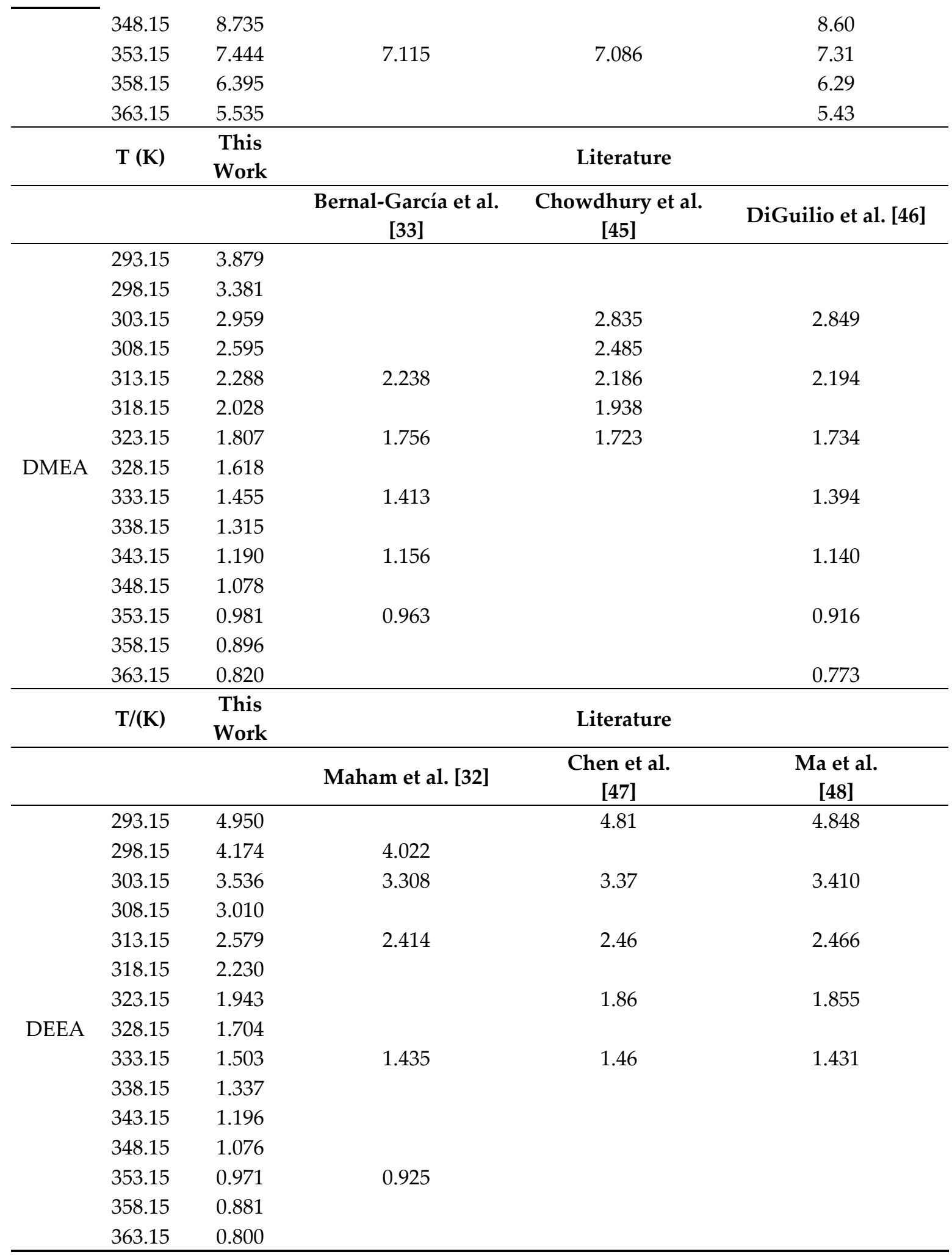

Table 11. Viscosities $\eta$ (mPa.s) and viscosity deviation $\eta^{E}$ (mPa $\cdot \mathrm{s}$ ) of MDEA (1) $+\mathrm{MEA}(2)+\mathrm{H}_{2} \mathrm{O}(3)$ mixtures.

\begin{tabular}{ccccccccc}
\hline Mixtures & \multicolumn{7}{c}{ MDEA/MEA } \\
\hline (Mass\%/Mass\%) & \multicolumn{10}{c}{$\mathbf{1 5 / 1 5}$} & \multicolumn{2}{c}{$\mathbf{2 0 / 1 0}$} & \multicolumn{2}{c}{$\mathbf{2 5 / 5}$} & \multicolumn{2}{c}{$\mathbf{3 0 / 0}$} \\
\hline${ }^{\mathrm{a}} \boldsymbol{x}_{\mathbf{1}} / \boldsymbol{x}_{\mathbf{2}}$ & $\mathbf{0 . 0 2 9 6 / 0 . 0 5 7 7}$ & $\mathbf{0 . 0 3 9 8 / 0 . 0 3 8 8}$ & $\mathbf{0 . 0 5 0 2 / 0 . 0 1 9 6}$ & $\mathbf{0 . 0 6 0 9 / 0 . 0 0 0 0}$ \\
\hline $\mathrm{T} /(\mathbf{K})$ & $\boldsymbol{\eta}$ & $\boldsymbol{\eta}^{\boldsymbol{E}}$ & $\boldsymbol{\eta}$ & $\boldsymbol{\eta}^{\boldsymbol{E}}$ & $\boldsymbol{\eta}$ & $\boldsymbol{\eta}^{\boldsymbol{E}}$ & $\boldsymbol{\eta}$ & $\boldsymbol{\eta}^{\boldsymbol{E}}$ \\
\hline 293.15 & 3.263 & -1.976 & 3.436 & -2.400 & 3.581 & -2.863 & 3.712 & -3.352 \\
\hline
\end{tabular}




\begin{tabular}{ccccccccc}
\hline 298.15 & 2.780 & -1.337 & 2.917 & -1.635 & 3.034 & -1.961 & 3.136 & -2.311 \\
303.15 & 2.385 & -0.900 & 2.496 & -1.107 & 2.593 & -1.334 & 2.673 & -1.584 \\
308.15 & 2.065 & -0.599 & 2.156 & -0.744 & 2.235 & -0.904 & 2.301 & -1.082 \\
313.15 & 1.803 & -0.390 & 1.879 & -0.489 & 1.946 & -0.601 & 1.995 & -0.735 \\
318.15 & 1.588 & -0.243 & 1.654 & -0.311 & 1.709 & -0.391 & 1.748 & -0.490 \\
323.15 & 1.410 & -0.141 & 1.467 & -0.185 & 1.512 & -0.244 & 1.544 & -0.318 \\
328.15 & 1.264 & -0.065 & 1.314 & -0.095 & 1.350 & -0.138 & 1.376 & -0.194 \\
333.15 & 1.140 & -0.012 & 1.184 & -0.029 & 1.215 & -0.061 & 1.236 & -0.104 \\
338.15 & 1.036 & 0.030 & 1.075 & 0.020 & 1.099 & -0.007 & 1.117 & -0.039 \\
343.15 & 0.947 & 0.058 & 0.979 & 0.051 & 0.998 & 0.030 & 1.017 & 0.010 \\
348.15 & 0.867 & 0.077 & 0.896 & 0.075 & 0.913 & 0.060 & 0.930 & 0.044 \\
353.15 & 0.797 & 0.090 & 0.824 & 0.092 & 0.841 & 0.082 & 0.853 & 0.068 \\
358.15 & 0.741 & 0.103 & 0.763 & 0.104 & 0.777 & 0.097 & 0.790 & 0.089 \\
363.15 & 0.712 & 0.133 & 0.722 & 0.126 & 0.738 & 0.125 & 0.747 & 0.116 \\
\hline
\end{tabular}

${ }^{\mathrm{a}} x=$ mole fraction.

Table 12. Viscosities $\eta$ (mPa.s) and viscosity deviation $\eta^{E}$ (mPa.s) of DMEA (1) + MEA (2) $+\mathrm{H}_{2} \mathrm{O}(3)$ mixtures.

\begin{tabular}{ccccccccc}
\hline Mixtures & \multicolumn{8}{c}{ DMEA/MEA } \\
\hline (Mass\%/Mass\%) & \multicolumn{1}{c}{$\mathbf{1 5 / 1 5}$} & \multicolumn{2}{c}{$\mathbf{2 0 / 1 0}$} & \multicolumn{2}{c}{$\mathbf{2 5 / 5}$} & \multicolumn{2}{c}{$\mathbf{3 0 / 0}$} \\
\hline${ }^{\mathrm{a}} \boldsymbol{x}_{\mathbf{1}} / \boldsymbol{x}_{\mathbf{2}}$ & $\mathbf{0 . 0 3 9 1 / 0 . 0 5 7 1}$ & $\mathbf{0 . 0 5 2 5} / \mathbf{0 . 0 3 8 3}$ & $\mathbf{0 . 0 6 6 0 / 0 . 0 1 9 3}$ & $\mathbf{0 . 0 7 9 7 / 0 . 0 0 0 0}$ \\
\hline $\mathrm{T} /(\mathbf{K})$ & $\boldsymbol{\eta}$ & $\boldsymbol{\eta}^{\boldsymbol{E}}$ & $\boldsymbol{\eta}$ & $\boldsymbol{\eta}^{\boldsymbol{E}}$ & $\boldsymbol{\eta}$ & $\boldsymbol{\eta}^{\boldsymbol{E}}$ & $\boldsymbol{\eta}$ & $\boldsymbol{\eta}^{\boldsymbol{E}}$ \\
\hline 293.15 & 3.523 & 1.130 & 3.744 & 1.734 & 4.079 & 2.456 & 4.245 & 3.013 \\
298.15 & 2.969 & 0.978 & 3.130 & 1.437 & 3.389 & 1.996 & 3.487 & 2.398 \\
303.15 & 2.512 & 0.832 & 2.644 & 1.197 & 2.848 & 1.639 & 2.898 & 1.928 \\
308.15 & 2.155 & 0.718 & 2.256 & 1.006 & 2.410 & 1.349 & 2.440 & 1.571 \\
313.15 & 1.866 & 0.624 & 1.943 & 0.852 & 2.064 & 1.126 & 2.079 & 1.296 \\
318.15 & 1.632 & 0.547 & 1.691 & 0.729 & 1.790 & 0.953 & 1.791 & 1.081 \\
323.15 & 1.439 & 0.482 & 1.485 & 0.629 & 1.565 & 0.813 & 1.557 & 0.909 \\
328.15 & 1.282 & 0.430 & 1.319 & 0.552 & 1.386 & 0.706 & 1.369 & 0.776 \\
333.15 & 1.149 & 0.386 & 1.180 & 0.489 & 1.235 & 0.616 & 1.212 & 0.666 \\
338.15 & 1.038 & 0.351 & 1.063 & 0.436 & 1.111 & 0.545 & 1.082 & 0.578 \\
343.15 & 0.942 & 0.318 & 0.962 & 0.390 & 1.001 & 0.481 & 0.973 & 0.507 \\
348.15 & 0.859 & 0.291 & 0.874 & 0.350 & 0.906 & 0.427 & 0.882 & 0.448 \\
353.15 & 0.788 & 0.267 & 0.800 & 0.318 & 0.827 & 0.384 & 0.805 & 0.401 \\
358.15 & 0.728 & 0.248 & 0.735 & 0.288 & 0.761 & 0.349 & 0.737 & 0.360 \\
363.15 & 0.701 & 0.257 & 0.703 & 0.289 & 0.711 & 0.328 & 0.686 & 0.333 \\
\hline
\end{tabular}

${ }^{\mathrm{a}} x=$ mole fraction.

Table 13. Viscosities $\eta$ (mPa.s) and viscosity deviation $\eta^{E}$ (mPa.s) of DEEA (1) + MEA (2) $+\mathrm{H}_{2} \mathrm{O}(3)$ mixtures.

\begin{tabular}{|c|c|c|c|c|c|c|c|c|}
\hline Mixtures & \multicolumn{8}{|c|}{ DEEA/MEA } \\
\hline (Mass\%/Mass\%) & \multicolumn{2}{|c|}{$15 / 15$} & \multicolumn{2}{|c|}{$20 / 10$} & \multicolumn{2}{|c|}{$25 / 5$} & \multicolumn{2}{|c|}{$30 / 0$} \\
\hline${ }^{\mathrm{a}} x_{1} / x_{2}$ & 0.0301 & 0.0577 & 0.040 & 0.0388 & 0.051 & 0.0196 & 0.0618 & 0.0000 \\
\hline$T /(K)$ & $\eta$ & $\eta^{E}$ & $\eta$ & $\eta^{E}$ & $\eta$ & $\eta^{E}$ & $\eta$ & $\eta^{E}$ \\
\hline 293.15 & 3.691 & 1.280 & 3.963 & 1.933 & 4.217 & 2.575 & 4.536 & 3.290 \\
\hline 298.15 & 3.086 & 1.085 & 3.281 & 1.577 & 3.464 & 2.063 & 3.689 & 2.595 \\
\hline 303.15 & 2.604 & 0.919 & 2.746 & 1.296 & 2.886 & 1.675 & 3.048 & 2.081 \\
\hline 308.15 & 2.220 & 0.781 & 2.325 & 1.075 & 2.435 & 1.378 & 2.552 & 1.691 \\
\hline 313.15 & 1.910 & 0.669 & 1.991 & 0.904 & 2.078 & 1.147 & 2.165 & 1.393 \\
\hline 318.15 & 1.662 & 0.580 & 1.726 & 0.769 & 1.795 & 0.967 & 1.860 & 1.163 \\
\hline
\end{tabular}




\begin{tabular}{lllllllll}
\hline 323.15 & 1.460 & 0.506 & 1.507 & 0.658 & 1.565 & 0.823 & 1.617 & 0.984 \\
328.15 & 1.296 & 0.449 & 1.330 & 0.571 & 1.380 & 0.710 & 1.419 & 0.840 \\
333.15 & 1.159 & 0.401 & 1.182 & 0.498 & 1.229 & 0.621 & 1.259 & 0.728 \\
338.15 & 1.041 & 0.359 & 1.057 & 0.438 & 1.101 & 0.547 & 1.126 & 0.637 \\
343.15 & 0.942 & 0.323 & 0.953 & 0.388 & 0.993 & 0.484 & 1.016 & 0.563 \\
348.15 & 0.858 & 0.294 & 0.874 & 0.357 & 0.900 & 0.431 & 0.920 & 0.499 \\
353.15 & 0.782 & 0.266 & 0.797 & 0.321 & 0.822 & 0.388 & 0.842 & 0.450 \\
358.15 & 0.719 & 0.243 & 0.730 & 0.289 & 0.752 & 0.349 & 0.771 & 0.405 \\
363.15 & 0.686 & 0.246 & 0.691 & 0.283 & 0.696 & 0.320 & 0.708 & 0.365 \\
\hline
\end{tabular}

${ }^{\mathrm{a}} x=$ mole fraction.

The viscosity deviation of the mixtures was calculated as follows:

$$
\eta^{E}=\eta-\sum_{i=1}^{n} x_{i} \eta_{i}^{0}
$$

where $\eta, \eta_{i}^{0}, \eta^{E}$, and $x_{i}$ refer to the viscosity of the mixture, viscosity of the pure component, viscosity deviation of the mixture, and mole fraction, respectively. Here, $n=3$ represents the ternary mixture and the subscripts are as follows: $i=1$ for the tertiary amine, $i=2$ for the primary amine (MEA), and $i=3$ for $\mathrm{H}_{2} \mathrm{O}$.

The viscosity deviation $\eta^{E}$ is a property that provides a qualitative measure of intermolecular interactions between component molecules in a liquid mixture. A negative deviation $\left(\eta^{E}<0\right)$ indicates weak intermolecular interactions, while a positive deviation points out strong intermolecular interactions like H-bonding among unlike molecules in the mixture $[42,49]$. This method is widely used to analyze binary mixtures and the same analogy is adopted to study ternary mixtures [42]. The MDEA + MEA $+\mathrm{H}_{2} \mathrm{O}$ mixtures showed a negative deviation for $\eta^{E}$ at temperatures $<343.15 \mathrm{~K}$, and $\eta^{E}$ gradually increased with increasing temperature. As described by Domínguez et al. [50], the $\eta^{E}$ can become negative when intermolecular interactions between the molecules are stronger for the pure compounds than for their mixtures. The gradual increase of $\eta^{E}$ with increasing temperature implies that the strength of the interactions between the component molecules in mixtures decreases, which may be attributed to the breaking of the cohesive force in like molecules [51]. The mixtures of DMEA $+\mathrm{MEA}+\mathrm{H}_{2} \mathrm{O}$ and DEEA $+\mathrm{MEA}+\mathrm{H}_{2} \mathrm{O}$ showed a positive deviation for $\eta^{E}$ for the considered concentrations and temperatures. This revealed the association of strong intermolecular interactions of $\mathrm{H}$-bonds in the mixtures. The increase of temperature resulted in a decrease of $\eta^{E}$ owing to weakening of intermolecular interaction between unlike molecules.

Eyring [52] explained that in a liquid at rest, the molecules are constantly undergoing rearrangements. This was elaborated by Bird et al. [53] in terms of one molecule at a time escaping from its cage into an adjacent hole. A cage is an available space for a molecule to vibrate due to the surrounding closely packed neighboring molecules. An energy barrier of height $\Delta G^{*} / N_{A}$ represents the cage in which $\Delta G^{*}$ and $N_{A}$ are the free energy of activation for viscous flow and Avogadro's number, respectively.

The dynamic viscosity model for liquids found by Eyring [52] is given as follows:

$$
\eta=\frac{h N_{A}}{V} \exp \left(\frac{\Delta G^{*}}{R T}\right)
$$

where $\eta, V, h, N_{A}, R, T$, and $\Delta G^{*}$ refer to the viscosity, molar volume, Planck's constant, Avogadro's number, gas constant, temperature, and free energy of activation for viscous flow, respectively.

Equations (10) and (11) enable the determination of the excess free energy of activation for viscous flow $\Delta G^{E *}$ in terms of the viscosity and molar volume of the pure components: 


$$
\begin{gathered}
\ln (\eta V)=\ln (\eta V)_{\text {ideal }}+\frac{\Delta G^{E *}}{R T} \\
\ln (\eta V)=\sum_{i=1}^{n} x_{i} \ln \left(\eta_{i} V_{i}^{0}\right)+\frac{\Delta G^{E *}}{R T}
\end{gathered}
$$

where $\eta, \eta_{i}, V, V_{i}^{0}, x_{i}, R, T$, and $\Delta G^{E *}$ refer to the viscosity of the mixture, viscosity of pure component, molar volume of the mixture, molar volume of the pure component, mole fraction, gas constant, temperature, and excess free energy of activation for viscous flow, respectively. The subscripts are as follows: $i=1$ for the tertiary amine, $i=2$ for the primary amine (MEA), and $i=3$ for $\mathrm{H}_{2} \mathrm{O}$.

A Redlich-Kister-type [35] polynomial, as given by Equations (12)-(14), was proposed to fit the calculated $\Delta G^{E *}$ for the considered amine mixtures:

$$
\begin{gathered}
\Delta G^{E *}=\Delta G_{12}^{E *}+\Delta G_{23}^{E *}+\Delta G_{13}^{E *}, \\
\Delta G_{j k}^{E *}=x_{j} x_{k} \sum_{i=0}^{n} A_{i}\left(x_{j}-x_{k}\right)^{i}, \\
A_{i}=a+b(T)+c(T)^{2} .
\end{gathered}
$$

The correlation proposed for $\Delta G^{E *}$ was adopted to represent the measured viscosities, as illustrated in Figure 3. Due to the non-availability of measured density data beyond $343.15 \mathrm{~K}$, the correlation represents viscosities only in the temperature region of $293.15 \mathrm{~K}-343.15 \mathrm{~K}$. The calculated parameters of correlation for $\Delta G^{E *}$ are given in Tables 14-16. The reported AARD and AMD for the correlated viscosities of MDEA + MEA + $\mathrm{H}_{2} \mathrm{O}$, DMEA + MEA + $\mathrm{H}_{2} \mathrm{O}$, and DEEA + MEA $+\mathrm{H}_{2} \mathrm{O}$ mixtures are listed in Table 17 and show that the proposed correlations fit viscosity data with acceptable accuracy.

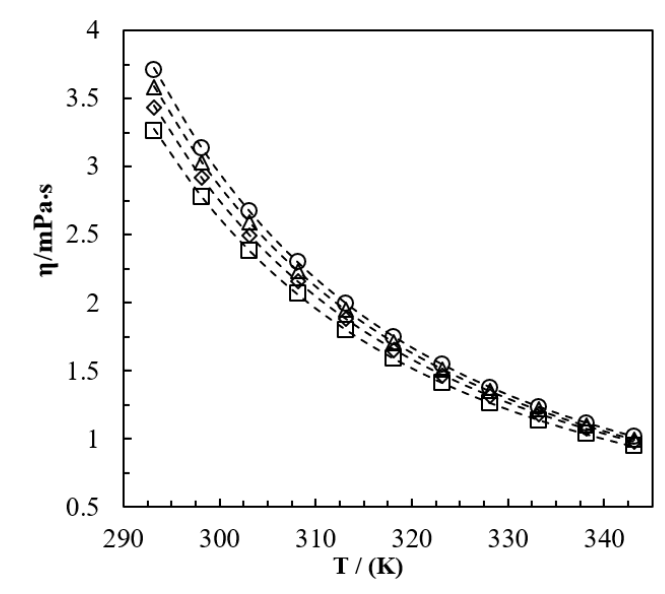

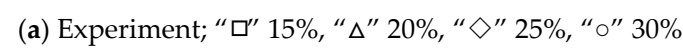
(mass\% MDEA), correlation; "---".

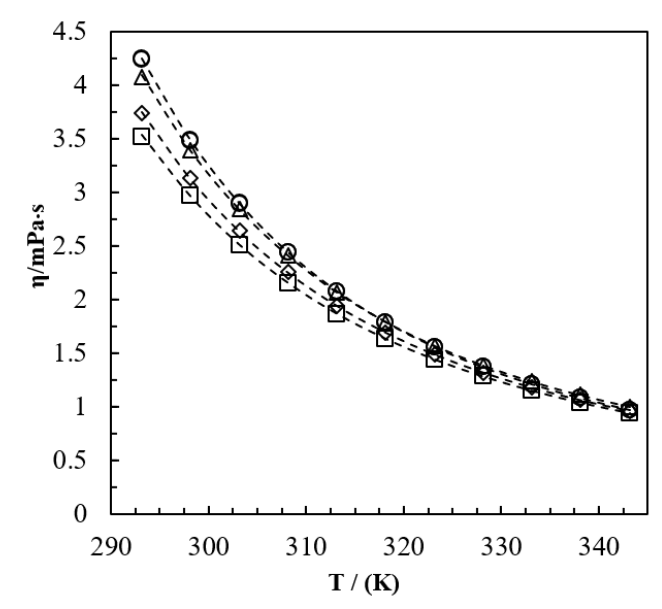

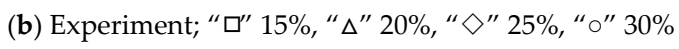
(mass\% DMEA), correlation; "---". 


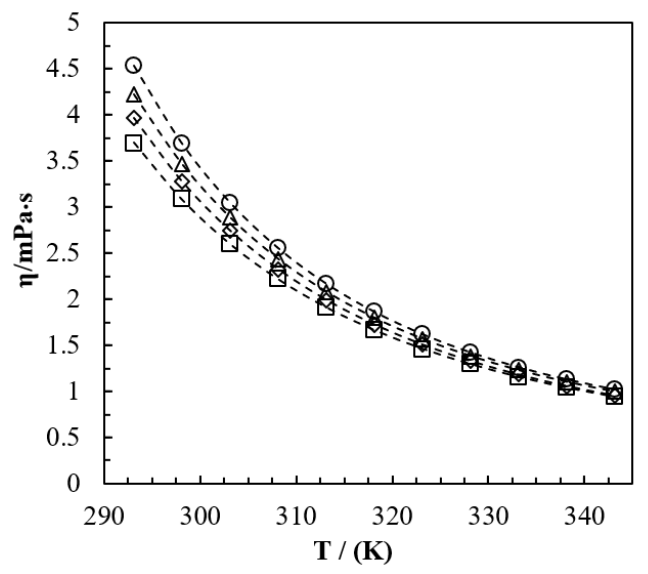

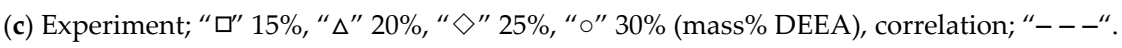

Figure 3. Viscosity of: (a) MDEA + MEA $+\mathrm{H}_{2} \mathrm{O}$, (b) DMEA + MEA $+\mathrm{H}_{2} \mathrm{O}$, and (c) DEEA + $\mathrm{MEA}+\mathrm{H}_{2} \mathrm{O}$ mixtures in the temperature range $293.15 \mathrm{~K}-343.15 \mathrm{~K}$.

Table 14. Binary parameters $A_{0}, A_{1}$, and $A_{2}$ of the equation $\Delta G_{j k}^{E *}=x_{j} x_{k} \sum_{i=0}^{n} A_{i}\left(x_{j}-x_{k}\right)^{i}$ for the excess free energy of activation for the viscous flow of MDEA (1) + MEA (2) + $\mathrm{H}_{2} \mathrm{O}$ (3).

\begin{tabular}{ccccc}
\hline \multirow{2}{*}{ Parameters } & \multicolumn{3}{c}{ Binary Pair } \\
\cline { 3 - 5 }$A_{0}$ & $a$ & $793,598.3561$ & $29,742.8180$ & $88,484.8967$ \\
& $b$ & -4103.0875 & -151.4883 & -415.9737 \\
& $c$ & 0.0695 & 0.9416 & 1.1885 \\
$A_{1}$ & $a$ & $-24,596,691.6004$ & $-34,368.3693$ & $-100,459.5203$ \\
& $b$ & 144054.1895 & 176.3634 & 472.7640 \\
& $c$ & -147.3226 & 0.1721 & -0.0422 \\
$A_{2}$ & $a$ & $-992,156,463.1846$ & $39,623.1737$ & $114,056.3754$ \\
& $b$ & $6,459,639.6117$ & -202.4417 & -536.0680 \\
& $c$ & $-11,029.3913$ & 0.2259 & 0.6852 \\
\hline
\end{tabular}

Table 15. Binary parameters $A_{0}, A_{1}$, and $A_{2}$ of the equation $\Delta G_{j k}^{E *}=x_{j} x_{k} \sum_{i=0}^{n} A_{i}\left(x_{j}-x_{k}\right)^{i}$ for the excess free energy of activation for the viscous flow of DMEA (1) + MEA (2) + $\mathrm{H}_{2} \mathrm{O}$ (3).

\begin{tabular}{ccccc}
\hline \multirow{2}{*}{ Parameters } & \multicolumn{3}{c}{ Binary Pair } \\
\cline { 3 - 5 }$A_{0}$ & $a$ & $408,836.2339$ & $23,045.8957$ & $121,961.3271$ \\
& $b$ & -2025.9328 & -111.1510 & -594.2230 \\
& $c$ & -1.7551 & 0.3358 & 1.2015 \\
$A_{1}$ & $a$ & $-7,605,815.8343$ & $-26,647.3964$ & $-142,650.2697$ \\
& $b$ & $30,647.5124$ & 129.8558 & 695.9285 \\
& $c$ & 7.3689 & 0.1302 & -0.18829 \\
$A_{2}$ & $a$ & $200,073,604.4909$ & $30,794.61597$ & $166,795.8337$ \\
& $b$ & $-1,158,470.4621$ & -148.3353 & -812.9574 \\
& $c$ & 1738.2732 & 0.7219 & 1.4276 \\
\hline
\end{tabular}

Table 16. Binary parameters $A_{0}, A_{1}$, and $A_{2}$ of the equation $\Delta G_{j k}^{E *}=x_{j} x_{k} \sum_{i=0}^{n} A_{i}\left(x_{j}-x_{k}\right)^{i}$ for the excess free energy of activation for the viscous flow of DEEA (1) + MEA (2) + $\mathrm{H}_{2} \mathrm{O}$ (3).

\begin{tabular}{lccc}
\hline \multirow{2}{*}{ Parameters } & \multicolumn{3}{c}{ Binary Pair } \\
\cline { 2 - 4 } & DEEA + MEA & MEA + $\mathrm{H}_{2} \mathrm{O}$ & DEEA + $\mathrm{H}_{2} \mathrm{O}$ \\
\hline
\end{tabular}




\begin{tabular}{ccccc}
\hline$A_{0}$ & $a$ & $25,126.2870$ & 6568.5853 & $187,358.9813$ \\
& $b$ & 1235.2155 & 6.8875 & -956.1233 \\
& $c$ & -1.4932 & 0.0215 & 1.6908 \\
$A_{1}$ & $a$ & $-29,279,977.3999$ & -6903.8084 & $-212,891.0602$ \\
& $b$ & $170,793.9954$ & -12.0764 & 1087.3001 \\
& $c$ & -281.5476 & 0.6502 & -0.8913 \\
$A_{2}$ & $a$ & $1,130,127,942.1759$ & 7134.8943 & $241,892.0192$ \\
& $b$ & $-7,848,704.4368$ & 20.9358 & -1233.8639 \\
& $c$ & $13,825.2946$ & 0.4399 & 2.0013 \\
\hline
\end{tabular}

Table 17. Average absolute relative $(A A R D)$ and absolute maximum $(A M D)$ deviations calculated based on correlations proposed using Equations (12)-(14).

\begin{tabular}{ccc}
\hline Mixture & AARD (\%) & AMD (mPa·s) \\
\hline MDEA + MEA + $\mathrm{H}_{2} \mathrm{O}$ & 0.14 & 0.013 \\
DMEA + MEA + $\mathrm{H}_{2} \mathrm{O}$ & 0.10 & 0.013 \\
DEEA + MEA + $\mathrm{H}_{2} \mathrm{O}$ & 0.07 & 0.010 \\
\hline
\end{tabular}

The supplementary materials provide the information of the used MATLAB program for the calculation of parameters involve in viscosity correlation.

According to Meyer et al. [54], molecular interactions in liquid mixtures can be studied by adopting $\Delta G^{E *}$, similar to the $\eta^{E}$. Studies performed in References [41,55-57] suggested that a positive deviation of $\Delta G^{E *}$ indicates strong intermolecular interactions, such as H-bonds among unlike molecules, while a negative deviation of $\Delta G^{E *}$ signifies weak molecular interactions, such as dispersive forces.

The mixtures examined in this study demonstrated positive deviations for $\Delta G^{E *}$ for the considered amine concentrations and temperatures, indicating the presence of strong intermolecular interactions like $\mathrm{H}$-bonds between the molecules in the mixtures. The presence of $(-\mathrm{OH})$ and $\left(-\mathrm{NH}_{2}\right)$ groups in amines contributes to the formation of $\mathrm{H}$-bonds between unlike molecules. For the MDEA $+\mathrm{MEA}+\mathrm{H}_{2} \mathrm{O}$ mixtures, the highest $\Delta G^{E *}$ was reported for the mixture of 30 mass $\%$ MDEA +0 mass $\%$ $\mathrm{MEA}+70$ mass $\% \mathrm{H}_{2} \mathrm{O}$. The highest $\Delta G^{E *}$ for DEEA $+\mathrm{MEA}+\mathrm{H}_{2} \mathrm{O}$ was reported for the mixture of 30 mass $\%$ DEEA + 0 mass $\%$ MEA +70 mass $\% \mathrm{H}_{2} \mathrm{O}$, while for DMEA $+\mathrm{MEA}+\mathrm{H}_{2} \mathrm{O}$, the highest $\Delta G^{E *}$ was reported for the mixture of 30 mass $\%$ DMEA +0 mass $\% \mathrm{MEA}+70$ mass $\% \mathrm{H}_{2} \mathrm{O}$. The increases of MEA concentration gradually decreased the $\Delta G^{E *}$ for all mixtures, as shown in the Figure 4 .

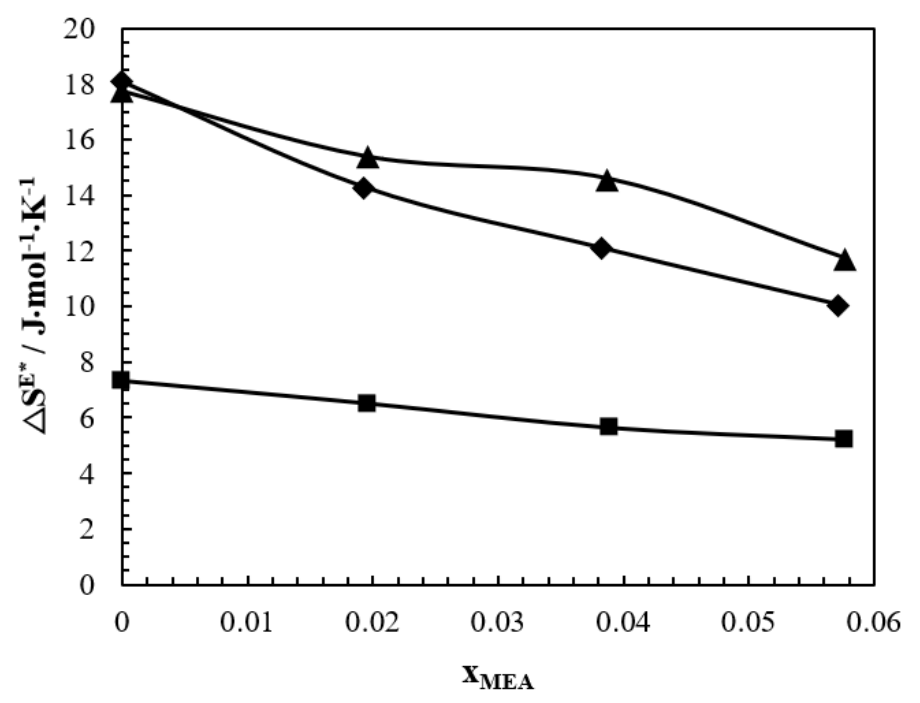

Figure 4. Excess free energy $\Delta G^{E *}$ of activation for the viscous flow of " $\mathbf{\square}^{\prime}-\mathrm{MDEA}+\mathrm{MEA}+\mathrm{H}_{2} \mathrm{O}$,

" $"$ "DMEA + MEA + $\mathrm{H}_{2} \mathrm{O}$, and " $\boldsymbol{\Delta} "-\mathrm{DEEA}+\mathrm{MEA}+\mathrm{H}_{2} \mathrm{O}$ at 293.15 K. 
The slope of the excess free energy of activation $\Delta G^{E *}$ against temperature $T$ at certain mole fractions gives the excess entropy of activation $\Delta S^{E *}$ for the viscous flow:

$$
\Delta S^{E *}=-\left[\frac{\partial \Delta G^{E *}}{\partial T}\right]
$$

Figure 5 shows the excess entropy of activation $\Delta S^{E *}$ for the viscous flow of MDEA + MEA + $\mathrm{H}_{2} \mathrm{O}, \mathrm{DMEA}+\mathrm{MEA}+\mathrm{H}_{2} \mathrm{O}$, and DEEA + MEA $+\mathrm{H}_{2} \mathrm{O}$ in the temperature range of $293.15 \mathrm{~K}-343.15 \mathrm{~K}$ over the whole range of concentrations. The values for $\Delta S^{E *}$ were determined using Equation (15). Figure 5 reveals that the excess entropy $\Delta S^{E *}$ followed the same trend as $\Delta G^{E *}$, that is, $\Delta S^{E *}$ decreased with the increase of MEA concentration in the mixture. A maximum value for $\Delta S^{E *}$ was observed at solutions with 0 mass $\%$ MEA.

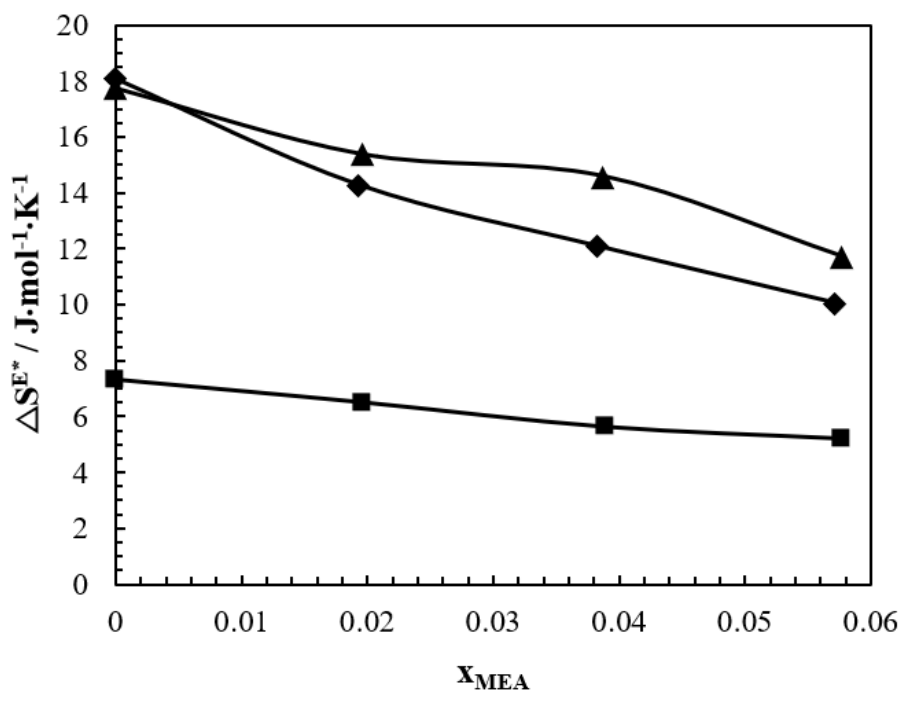

Figure 5. Excess entropy of activation $\Delta S^{E *}$ for the viscous flow of "⿴囗十 $-\mathrm{MDEA}+\mathrm{MEA}+\mathrm{H}_{2} \mathrm{O}$, " $\mathrm{DMEA}+\mathrm{MEA}+\mathrm{H}_{2} \mathrm{O}$, and “ $\boldsymbol{\Delta}$ " $-\mathrm{DEEA}+\mathrm{MEA}+\mathrm{H}_{2} \mathrm{O}$ for a range of MEA mole fractions.

\section{Conclusions}

This paper discusses the densities and viscosities of MDEA $+\mathrm{MEA}+\mathrm{H}_{2} \mathrm{O}$, DMEA $+\mathrm{MEA}+\mathrm{H}_{2} \mathrm{O}$, and DEEA + MEA $+\mathrm{H}_{2} \mathrm{O}$ mixtures at different concentrations of 15/15, 20/10, 25/5, and 30/0 for mass\% (tertiary amine; MDEA, DMEA and DEEA)/mass\% (primary amine; MEA) and temperatures.

The density of the mixtures was measured in the temperature range from $293.15 \mathrm{~K}$ to $343.15 \mathrm{~K}$. The density of the mixtures increased with the increase of MDEA concentration and the density decreased with the increase of temperature for MDEA + MEA $+\mathrm{H}_{2} \mathrm{O}$ mixtures. For the mixtures of $\mathrm{DMEA}+\mathrm{MEA}+\mathrm{H}_{2} \mathrm{O}$ and DEEA $+\mathrm{MEA}+\mathrm{H}_{2} \mathrm{O}$, the density decreased with the increase of DMEA and DEEA concentrations and the density decreased with the increase of temperature. The excess volume $V^{E}$ of the mixtures was determined and were correlated according to a Redlich-Kister-type polynomial to represent the measured densities. A negative sign of the excess volume $V^{E}$ indicates effective packing of the molecules and the presence of $\mathrm{H}$-bonding among the unlike molecules. The proposed correlation was able to fit the density data with the acceptable accuracies of $0.013 \%, 0.004 \%$, and $0.005 \%$ for $A A R D$ and $0.4 \mathrm{~kg} \cdot \mathrm{m}^{-3}, 0.3 \mathrm{~kg} \cdot \mathrm{m}^{-3}$, and $0.3 \mathrm{~kg} \cdot \mathrm{m}^{-3}$ for AMD for the MDEA + MEA + $\mathrm{H}_{2} \mathrm{O}, \mathrm{DMEA}+\mathrm{MEA}+\mathrm{H}_{2} \mathrm{O}$, and DEEA + MEA + $\mathrm{H}_{2} \mathrm{O}$ mixtures, respectively.

The viscosity of the mixtures was measured in the temperature range from $293.15 \mathrm{~K}$ to $363.15 \mathrm{~K}$. The viscosity of the mixture increased with the increase of MDEA, DMEA, and DEEA concentration in the mixtures and the viscosity decreased with the increase of temperature. The viscosity deviation $\eta^{E}$ was negative for the MDEA $+\mathrm{MEA}+\mathrm{H}_{2} \mathrm{O}$ at low temperatures, indicating weak intermolecular interactions in the mixture compared to the pure liquids. A positive $\eta^{E}$ was reported for the DMEA $+\mathrm{MEA}+\mathrm{H}_{2} \mathrm{O}$ and DEEA $+\mathrm{MEA}+\mathrm{H}_{2} \mathrm{O}$ mixtures for the considered temperature range, signifying the presence of strong intermolecular interactions, such as H-bonds, in the mixtures. The excess free 
energy of activation $\Delta G^{E *}$ for viscous flow, as described by Eyring, showed positive values for all mixtures for the temperature range. This highlights the existence of strong intermolecular interactions, such as H-bonds, between the molecules in the mixtures. The correlation proposed for the calculated $\Delta G^{E *}$ from measured densities and viscosities was able to fit the $\Delta G^{E *}$ with $0.15 \%$, $0.09 \%$, and $0.07 \%$ for $A A R D$ for the MDEA + MEA $+\mathrm{H}_{2} \mathrm{O}$, DMEA + MEA + $\mathrm{H}_{2} \mathrm{O}$, and DEEA + MEA + $\mathrm{H}_{2} \mathrm{O}$ mixtures, respectively.

Supplementary Materials: The supplementary materials are available online at www.mdpi.com/2311$5521 / 5 / 1 / 27 / s 1$.

Author Contributions: Supervision, L.E.Ø., K.J.J. and D.A.E.; Writing-original draft, S.S.K.

Funding: This work was funded by the Ministry of Education and Research of the Norwegian Government.

Conflicts of Interest: The authors declare no conflict of interest.

\section{References}

1. Metz, B.; Davidson, O.; Coninck, H.D.; Loos, M.; Meyer, L. IPCC Special Report on Carbon Dioxide Capture and Storage; Cambridge University Press: New York, NY, USA, 2005.

2. Idem, R.; Supap, T.; Shi, H.; Gelowitz, D.; Ball, M.; Campbell, C.; Tontiwachwuthikul, P. Practical experience in post-combustion $\mathrm{CO}_{2}$ capture using reactive solvents in large pilot and demonstration plants. Int. J. Greenh. Gas Control 2015, 40, 6-25, doi:10.1016/j.ijggc.2015.06.005.

3. Singh, A.; Stéphenne, K. Shell Cansolv $\mathrm{CO}_{2}$ capture technology: Achievement from First Commercial Plant. Energy Procedia 2014, 63, 1678-1685, doi:10.1016/j.egypro.2014.11.177.

4. Bernhardsen, I.M.; Knuutila, H.K. A review of potential amine solvents for $\mathrm{CO}_{2}$ absorption process: Absorption capacity, cyclic capacity and pKa. Int. J. Greenh. Gas Control 2017, 61, 27-48, doi:10.1016/j.ijggc.2017.03.021.

5. da Silva, E.F.; Svendsen, H.F. Computational chemistry study of reactions, equilibrium and kinetics of chemical $\mathrm{CO}_{2}$ absorption. Int. J. Greenh. Gas Control 2007, 1, 151-157, doi:10.1016/S1750-5836(07)00022-9.

6. Idris, Z; Eimer, D.A. Density measurements of unloaded and $\mathrm{CO}_{2}$ loaded 3 - Amino -1- propanol solutions at temperatures (293.15 to 353.15) K. J. Chem. Eng. Data 2016, 61, 173-181.

7. Hartono, A.; da Silva, E.F.; Grasdalen, H.; Svendsen, H.F. Qualitative Determination of Species in DETA- $\mathrm{H}_{2} \mathrm{O}-\mathrm{CO}_{2}$ System Using $13 \mathrm{C}$ NMR Spectra. Ind. Eng. Chem. Res. 2007, 46, 249-254, doi:10.1021/ie0603868.

8. Hartono, A.; Svendsen, H.F. Density, viscosity, and excess properties of aqueous solution of diethylenetriamine (DETA). J. Chem. Thermodyn. 2009, 41, 973-979, doi:10.1016/j.jct.2008.11.012.

9. Jiang, W.; Luo, X.; Gao, H.; Liang, Z.; Liu, B.; Tontiwachwuthikul, P.; Hu, X. A comparative kinetics study of $\mathrm{CO}_{2}$ absorption into aqueous DEEA/MEA and DMEA/MEA blended solutions Aiche J. 2017, 64, 13501358, doi:10.1002/aic.16024.

10. Kim, I.; Svendsen, H.F. Comparative study of the heats of absorption of post-combustion $\mathrm{CO}_{2}$ absorbents. Int. J. Greenh. Gas Control 2011, 5, 390-395, doi:10.1016/j.ijggc.2010.05.003.

11. Zhang, J.; Fennell, P.S.; Trusler, J.P.M. Density and Viscosity of Partially Carbonated Aqueous Tertiary Alkanolamine Solutions at Temperatures between (298.15 and 353.15) K. J. Chem. Eng. Data 2015, 60, 2392 2399, doi:10.1021/acs.jced.5b00282.

12. Kidnay, A.J.; Parrish, W.R. Fundamentals of Natural Gas Processing; Taylor \& Francis Group: Boca Raton, FL, USA, 2006.

13. Jou, F.-Y.; Carroll, J.J.; Mather, A.E.; Otto, F.D. The solubility of carbon dioxide and hydrogen sulfide in a $35 \mathrm{wt} \%$ aqueous solution of methyldiethanolamine. Can. J. Chem. Eng. 1993, 71, 264-268, doi:10.1002/cjce.5450710213.

14. Rinker, E.B.; Sami, S.A.; Sandall, O.C. Kinetics and modelling of carbon dioxide absorption into aqueous solutions of N-methyldiethanolamine. Chem. Eng. Sci. 1995, 50, 755-768, doi:10.1016/0009-2509(94)00444-V.

15. Daviet, G.R.; Sundermann, R.; Donnelly, S.T.; Bullin, J.A. Dome's North Caroline Plant Successful Conversion to MDEA. In Proceedings of the Sixty-Third GPA Annual Convention. Available online: https://www.bre.com/PDF/Dome's-North-Caroline-Plant-Successful-Conversion-to-MDEA.pdf (accessed on 3 January 2020). 
16. Blanc, C.; Grall, M.; Demarais, G. Part played by degradation products in the corrosion of gas sweetening plants using DEA and MDEA. In Proceedings of the Annual Oklahoma University gas conditioning conference, Norman, OK, USA, 8 March 1982.

17. Kim, C.J.; Savage, D.W. Kinetics of carbon dioxide reaction with diethylaminoethanol in aqueous solutions. Chem. Eng. Sci. 1987, 42, 1481-1487, doi:10.1016/0009-2509(87)85020-0.

18. Henni, A.; Li, J.; Tontiwachwuthikul, P. Reaction kinetics of $\mathrm{CO}_{2}$ in Aqueous 1-Amino-2-Propanol, 3Amino-1-Propanol, and Dimethylmonoethanolamine solutions in the temperature range of 298-313 K using the stopped-flow technique. Ind. Eng. Chem. Res. 2008, 47, 2213-2220, doi:10.1021/ie070587r.

19. Chakravarty, T.; Phukan, U.K.; Weilund, R.H. Reaction of Acid gases with mixtures of amines. Chem. Eng. Prog. 1985, 40, 32-36.

20. Ramachandran, N.; Aboudheir, A.; Idem, R.; Tontiwachwuthikul, P. Kinetics of the Absorption of $\mathrm{CO}_{2}$ into Mixed Aqueous Loaded Solutions of Monoethanolamine and Methyldiethanolamine. Ind. Eng. Chem. Res. 2006, 45, 2608-2616, doi:10.1021/ie0505716.

21. Conway, W.; Bruggink, S.; Beyad, Y.; Luo, W.; Melián-Cabrera, I.; Puxty, G.; Feron, P. CO2 absorption into aqueous amine blended solutions containing monoethanolamine (MEA), N,N-dimethylethanolamine (DMEA), N,N-diethylethanolamine (DEEA) and 2-amino-2-methyl-1-propanol (AMP) for post-combustion capture processes. Chem. Eng. Sci. 2015, 126, 446-454, doi:10.1016/j.ces.2014.12.053.

22. Glasscock, D.A.; Critchfield, J.E.; Rochelle, G.T. $\mathrm{CO}_{2}$ absorption/desorption in mixtures of methyldiethanolamine with monoethanolamine or diethanolamine. Chem. Eng. Sci. 1991, 46, 2829-2845, doi:10.1016/0009-2509(91)85152-N.

23. Li, M.H.; Shen, K.P. Densities and solubilities of solutions of Carbon Dioxide in water+Monoethanolamine+N-Methyldiethanolamine. J. Chem. Eng. Data 1992, 37, 288-290.

24. Li, M.-H.; Lie, Y.-C. Densities and viscosities of solutions of Monoethanolamine + N-Methyldiethanolamine + water and Monoethanolamine + 2-Amino-2-methyl-1-propanol + water. J. Chem. Eng. Data 1994, 39, 444447.

25. Hagewiesche, D.P.; Ashour, S.S.; Sandall, O.C. Solubility and Diffusivity of Nitrous Oxide in Ternary Mixtures of Water, Monoethanolamine and N-Methyldiethanolamine and Solution Densities and Viscosities. J. Chem. Eng. Data 1995, 40, 627-629, doi:10.1021/je00019a020.

26. Harvey, A.H. Thermodynamic Properties of Water; NIST: Boulder, CO, USA, 1998.

27. JCGM. Evaluation of measurement data-Supplement 1 to the "Guide to the expression of uncertainty in measurement"-Propagation of distributions using a Monte Carlo method. Available online: https://www.bipm.org/utils/common/documents/jcgm/JCGM_101_2008_E.pdf (accessed on 3 January 2020).

28. Ellison, S.L.R.; Williams, A. Quantifying Uncertainty in Analytical Measurement. Available online: https://www.eurachem.org/images/stories/Guides/pdf/QUAM2012_P1.pdf (accessed on 3 January 2020).

29. Pinto, D.D.D.; Monteiro, J.G.M.S.; Johnsen, B.; Svendsen, H.F.; Knuutila, H. Density measurements and modelling of loaded and unloaded aqueous solutions of MDEA (N-methyldiethanolamine), DMEA (N,Ndimethylethanolamine), DEEA (diethylethanolamine) and MAPA (N-methyl-1,3-diaminopropane). Int. J. Greenh. Gas Control 2014, 25, 173-185, doi:10.1016/j.ijggc.2014.04.017.

30. Hawrylak, B.; Bruke, S.E.; Palepu, R. Partial molar and excess volumes and adiabatic compressibilities of binary mixtures of ethanolamines with water. J. Solut. Chem. 2000, 29, 575-593.

31. Maham, Y.; Teng, T.T.; Mather, A.E.; Hepler, L.G. Volumetric properties of (water + diethanolamine) systems. Can. J. Chem 1995, 73, 1514-1519.

32. Maham, Y.; Lebrette, L.; Mather, A.E. Viscosities and Excess Properties of Aqueous Solutions of Mono- and Diethylethanolamines at Temperatures between 298.15 and 353.15 K. J. Chem. Eng. Data 2002, 47, 550-553, doi:10.1021/je015528d.

33. Bernal-García, J.M.; Hall, K.R.; Estrada-Baltazar, A.; Iglesias-Silva, G.A. Density and viscosity of aqueous solutions of $\mathrm{N}, \mathrm{N}$-dimethylethanolamine at $\mathrm{p}=0.1 \mathrm{MPa}$ from $\mathrm{T}=(293.15$ to 363.15) K. J. Chem. Thermodyn. 2005, 37, 762-767, doi:10.1016/j.jct.2004.11.016.

34. Zhang, F.-Q.; Li, H.-P.; Dai, M.; Zhao, J.-P.; Chao, J.P. Volumetric properties of binary mixtures of water with ethanolamine alkyl derivatives. Thermochim. Acta 1995, 254, 347-357, doi:10.1016/0040-6031(94)02127A. 
35. Redlich, O.; Kister, A.T. Algebraic representation of thermodynamic properties and the classification of solutions. Ind. Eng. Chem. 1948, 40, 345-348.

36. Domínguez, M.; Rodríguez, S.; López, M.C.; Royo, F.M.; Urieta, J.S. Densities and Viscosities of the Ternary Mixtures 1-Butanol + 1-Chlorobutane + 1-Butylamine and 2-Methyl-1-propanol + 1-Chlorobutane + 1Butylamine at 298.15 K. J. Chem. Eng. Data 1996, 41, 37-42, doi:10.1021/je950113b.

37. Samanta, A.; Bandyopadhyay, S.S. Density and Viscosity of Aqueous Solutions of Piperazine and (2Amino-2-methyl-1-propanol + Piperazine) from 298 to 333 K. J. Chem. Eng. Data 2006, 51, 467-470, doi:10.1021/je050378i.

38. Hartono, A.; Mba, E.O.; Svendsen, H.F. Physical properties of partially $\mathrm{CO}_{2}$ loaded aqueous monoethanolamine (MEA). J. Chem. Eng. Data 2014, 59, 1808-1816.

39. Weiland, R.H.; Dingman, J.C.; Cronin, D.B.; Browning, G.J. Density and viscosity of some partially carbonated aqueous alkanolamine solutions and their blends. J. Chem. Eng. Data 1998, 43, 378-382.

40. Moioli, S.; Pellegrini, L.A. Physical properties of PZ solution used as a solvent for $\mathrm{CO}_{2}$ removal. Chem. Eng. Res. Des. 2015, 93, 720-726, doi:10.1016/j.cherd.2014.06.016.

41. Bhatia, S.C.; Bhatia, R.; Dubey, G.P. Studies on transport and thermodynamic properties of binary mixtures of octan-1-ol with chloroform, 1,2-dichloroethane and 1,1,2,2-tetrachloroethane at 298.15 and $308.15 \mathrm{~K}$. J. Mol. Liq. 2009, 144, 163-171, doi:10.1016/j.molliq.2008.11.003.

42. Ma, D.; Liu, Q.; Zhu, C.; Feng, H.; Ma, Y. Volumetric and viscometric properties of ternary solution of (Nmethyldiethanolamine + monoethanolamine + ethanol). J. Chem. Thermodyn. 2019, 134, 5-19, doi:10.1016/j.jct.2019.02.019.

43. Teng, T.T.; Maham, Y.; Hepler, L.G.; Mather, A.E. Viscosity of aqueous solutions of NMethyldiethanolamine and of Diethanolamine. J. Chem. Eng. Data 1994, 39, 290-293.

44. Kummamuru, N.B.; Idris, Z.; Eimer, D.A. Viscosity Measurement and Correlation of Unloaded and $\mathrm{CO}_{2}-$ Loaded Aqueous Solutions of N-Methyldiethanolamine-Piperazine. J. Chem. Eng. Data 2019, doi:10.1021/acs.jced.9b00021.

45. Chowdhury, F.I.; Akhtar, S.; Saleh, M.A.; Khandaker, M.U.; Amin, Y.M.; Arof, A.K. Volumetric and viscometric properties of aqueous solutions of some monoalkanolamines. J. Mol. Liq. 2016, 223, 299-314, doi:10.1016/j.molliq.2016.08.033.

46. DiGuilio, R.M.; Lee, R.J.; Schaeffer, S.T.; Brasher, L.L.; Teja, A.S. Densities and viscosity of the ethanolamines J. Chem. Eng. 1992, 37, 239-242.

47. Chen, S.; Zhang, L.; Zhang, Y.; Chen, S.; Chen, J. Density and viscosity of monoethylethanolamine $+\mathrm{H}_{2} \mathrm{O}$ and monoethylethanolamine+diethylethanolamine solutions for $\mathrm{CO}_{2}$ capture. Thermochim. Acta 2016, 642, 52-58, doi:10.1016/j.tca.2016.08.021.

48. Ma, D.; Zhu, C.; Fu, T.; Yuan, X.; Ma, Y. Volumetric and viscometric properties of binary and ternary mixtures of monoethanolamine, 2-(diethylamino) ethanol and water from (293.15 to 333.15) K. J. Chem. Thermodyn. 2019, 138, 350-365, doi:10.1016/j.jct.2019.06.032.

49. Fort, R.J.; Moore, W.R. Viscosities of binary liquid mixtures. Trans. Faraday Soc. 1966, 62, 1112-1119.

50. Domínguez, M.; Camacho, A.; López, M.C.; Royo, F.M.; Urieta, J.S. Excess molar volumes and excess viscosities of ternary mixtures (2-butanol + 1-chlorobutane + 1-butylamine) and (2-methyl-2-propanol + 1chlorobutane + 1-butylamine) at 298. 15 K. Can. J. Chem. 1995, 73, 896-901, doi:10.1139/v95-112.

51. Rafiee, H.R.; Ranjbar, S.; Poursalman, F. Densities and viscosities of binary and ternary mixtures of cyclohexanone, 1,4-dioxane and isooctane from $\mathrm{T}=(288.15$ to 313.15)K. J. Chem. Thermodyn. 2012, 54, 266271, doi:10.1016/j.jct.2012.05.005.

52. Eyring, H. Viscosity, Plasticity, and Diffusion as example of absolute reaction rates. J. Chem. Phys. 1936, 4, 283-291.

53. Bird, R.B.; Stewart, W.E.; Lightfoot, E.N. Transport PHENOMENA, 2nd ed.; John Wiley \& Sons, Inc.: Hoboken, NJ, USA, 2002.

54. Meyer, R.; Meyer, M.; Metzger, J.; Peneloux, A. Thermodynamic and physicochemical properties of binary solvent. J. Chim. Phys. Phys. Chim. Biol. 1971, 68, 406-412.

55. Domínguez, M.; Pardo, J.I.; Gascón, I.; Royo, F.M.; Urieta, J.S. Viscosities of the ternary mixture (2butanol+n-hexane+1-butylamine) at 298.15 and 313.15 K. Fluid Phase Equilibria 2000, 169, 277-292, doi:10.1016/S0378-3812(00)00332-0. 
56. Kinart, C.M.; Kinart, W.J.; Ćwiklińska, A. 2-Methoxyethanol-Tetrahydrofuran-Binary Liquid System. Viscosities, densities, excess molar volumes and excess Gibbs activation energies of viscous flow at various temperatures. J. Therm. Anal. Calorim. 2002, 68, 307-317, doi:10.1023/A:1014981921097.

57. Ćwiklińska, A.; Kinart, C.M. Thermodynamic and physicochemical properties of binary mixtures of nitromethane with $\{2$-methoxyethanol+2-butoxyethanol $\}$ systems at $\mathrm{T}=(293.15,298.15,303.15,308.15$, and 313.15)K. J. Chem. Thermodyn. 2011, 43, 420-429, doi:10.1016/j.jct.2010.10.016.

(C) 2020 by the authors. Licensee MDPI, Basel, Switzerland. This article is an open access article distributed under the terms and conditions of the Creative Commons Attribution (CC BY) license (http://creativecommons.org/licenses/by/4.0/). 